\title{
Isolation and Antimicrobial Activities of Phytochemicals from Parinari curatellifolia (Chrysobalanaceae)
}

\author{
Phillip Mawire, ${ }^{1}$ Winnie Mozirandi, ${ }^{1}$ Matthias Heydenreich, ${ }^{2}$ Godloves Fru Chi, ${ }^{3}$ \\ and Stanley Mukanganyama $\mathbb{D}^{1}$ \\ ${ }^{1}$ Department of Biochemistry, University of Zimbabwe, Mt. Pleasant, Harare, Zimbabwe \\ ${ }^{2}$ Universität Potsdam, OT Golm, Institut für Chemie, Haus 25, D/0.19 (Labor E/0.06-0.08), Karl-Liebknecht-Str. 24-25, \\ D-14476 Potsdam, Germany \\ ${ }^{3}$ Department of Organic Chemistry, University of Yaoundé I, P.O. Box 812, Yaoundé, Cameroon
}

Correspondence should be addressed to Stanley Mukanganyama; smukanganyama01@gmail.com

Received 22 August 2020; Revised 18 January 2021; Accepted 15 February 2021; Published 4 March 2021

Academic Editor: Abdelhakim Bouyahya

Copyright ( $\odot 2021$ Phillip Mawire et al. This is an open access article distributed under the Creative Commons Attribution License, which permits unrestricted use, distribution, and reproduction in any medium, provided the original work is properly cited.

\begin{abstract}
The widespread use of antimicrobial agents to treat infectious diseases has led to the emergence of antibiotic resistant pathogens. Plants have played a central role in combating many ailments in humans, and Parinari curatellifolia has been used for medicinal purposes. Seven extracts from P. curatellifolia leaves were prepared using serial exhaustive extraction of nonpolar to polar solvents. The microbroth dilution method was used to evaluate antimicrobial bioactivities of extracts. Five of the extracts were significantly active against at least one test microbe. Mycobacterium smegmatis was the most susceptible to most extracts. The methanol and ethanol extracts were the most active against M. smegmatis with an MIC of $25 \mu \mathrm{g} / \mathrm{mL}$. The hexane extract was the most active against Candida krusei with an MIC of $25 \mu \mathrm{g} / \mathrm{mL}$. None of the extracts significantly inhibited growth of Klebsiella pneumoniae and Staphylococcus aureus. Active extracts were selected for fractionation and isolation of pure compounds using gradient elution column chromatography. TLC analyses was carried out for pooling fractions of similar profiles. A total of 43 pools were obtained from 428 fractions. Pools 7 and 10 were selected for further isolation of single compounds. Four compounds, Pc4963r, Pc4962w, Pc6978p, and Pc6978o, were isolated. Evaluation of antimicrobial activities of Pc4963r, Pc4962w, and Pc6978p showed that the compounds were most active against C. krusei with MFC values ranging from 50 to $100 \mu \mathrm{g} / \mathrm{mL}$. Only Pc6978p was shown to be pure. Using spectroscopic analyses, the structure of Pc6978p was determined to be $\beta$-sitosterol. The antifungal effects of $\beta$-sitosterol were evaluated against $C$. krusei in vitro and on fabrics. Results showed that $\beta$-sitosterol reduced the growth of $C$. krusei attached to Mendy fabric by $83 \%$. Therefore, $P$. curatellifolia can be a source of lead compounds for prospective development of novel antimicrobial agents. Further work needs to be done to improve the antifungal activity of the isolated compound using quantitative structure-activity relationships.
\end{abstract}

\section{Introduction}

Infectious diseases remain the major cause of morbidity and mortality especially in the developing countries [1]. Resistance to common antimicrobial agents has led to high frequency of treatment failures and increase in treatment cost [2]. These incidences have resulted in prolonged hospital stay, leading to an increase of nosocomial infections $[3,4]$. The spread of antimicrobial resistance shows that even newly designed antimicrobial agents will have brief life expectancy of efficiency $[5,6]$.
Microbial resistance is reported to be acquired from different environmental sources including waste water, hospital surfaces, and contaminated textiles [7-9]. Clothes are often contaminated with certain pathogens when being worn or even after being washed [10]. Some bacteria tightly stick to the textile and tend to form biofilm which is difficult to remove [11], where resistance can be developed [7]. Contaminated textiles can cause health problems in the hospital environment [11]. The role of contaminated textiles, environmental surfaces, and medical devices in the transmission of health-associated pathogens and the development 
of microbial resistance has been well reported $[12,13]$. There is a need for efficient therapy for bacterial diseases [14] and to search for alternative compounds that can be used as surface and textile decontaminates [15].

Medicinal plants have been identified as important sources of natural antimicrobial compounds [16] and biocides [15]. Therapeutic value of these plants lies in some bioactive substances that produce a distinct physiological activity on the human body [17]. The most significant of these active phytochemicals are alkaloids, tannin, flavonoid, sterols, and phenolic compounds [18]. These compounds can be an alternative in treating microbial infections [6], as well as in formulation of alternative disinfectants [19].

$P$. curatellifolia is one of the most important medicinal plants for the people of Zimbabwe [20]. This plant has various documented uses in ethnomedicine including treatment of wound infections, cancer, pneumonia, fever, bacterial infections, and inflammation [21]. A number of studies have shown that extracts from P. curatellifolia have a number of pharmacological properties ranging from antibacterial activity to anticancer activity [20]. The pharmacological properties of $P$. curatellifolia are linked to the presence of pharmacologically active phytochemicals including saponins, flavonoid, tannins steroid, alkaloid, cardiac glycosides, carbohydrate, balsams, and terpenes [22]. Although there are a number of studies on the pharmacological properties of $P$. curatellifolia extracts, there has been a paucity of documented data on antimicrobial properties of pure compounds isolated from $P$. curatellifolia.

To date, several methods have been utilized when preparing samples to determine the antimicrobial action of plants [1]. These include preparation of crude extract using a variety of solvents, purification of active compounds from extracts, subsequent extraction with increasing solvent polarity, and distillation [16]. However, recent studies have shown enhanced activity of plant samples following fractionation of the extract and further purification of compounds $[1,22]$. The effects of $\beta$-sitosterol contaminated textiles were also assessed in an activity-guided procedure. $\beta$-Sitosterol is a natural phytosterol found in the cells and membranes of all oil producing plants [23]. $\beta$-Sitosterol has been shown to be a safe, nontoxic, effective nutritional supplement and has potential health benefits in many diverse clinical applications [24]. These include anti-inflammatory activity, chemopreventive effects, angiogenic effects, and antidiabetic effects [25].

The aim of this study was to isolate active compounds from $P$. curatellifolia and determine the antimicrobial activities of the isolated compounds on some common microbes implicated in nosocomial infection $[26,27]$ as well as on contaminated textiles. Isolation of these compounds may give a chance to evaluate the antimicrobial effects of the individual compounds as well as their synergistic effects with commercial antibiotics that are already in use. Isolated compounds from this study can then be used as templates for the production of new microbial agents or as supplements to the existing antimicrobial agents.

\section{Materials and Methods}

2.1. Plant Material. Fresh leaves of $P$. curatellifolia were collected between June and July of 2017 from Norton (latitude -17.88; longitude 30.70; situated at elevation 1364 meters above sea level) in Mashonaland west Province of Zimbabwe. The plant samples were authenticated at the National Herbarium (Harare, Zimbabwe) where a voucher specimen was made and deposited under the reference number C6E7. Permission to use the plant samples was granted by the Faculty of Higher Degrees Committee, Harare, Zimbabwe (HD/71/16).

2.2. Growth of Microbial Cells. Four microbial isolates drawn from the list of common and emerging nosocomial pathogens were used in the study $[25,26]$. M. smegmatis $155 \mathrm{mc}^{2}$ laboratory strain was obtained from the Department of Clinical Laboratory Sciences, University of Cape Town. A clinical strain of C. krusei and K. pneumoniae (ATCC 700603) was obtained from the Department of Medical Microbiology, University of Zimbabwe. Staphylococcus aureus (ATCC 9144) was obtained from the Department of Biological Science at the University of Botswana (Gaborone, Botswana).

2.3. Culture Media and Chemicals. All chemicals, reagents, and culture media used were purchased from Sigma-Aldrich Chemical Company (Taufkirchen, Germany). Organic solvents were distilled prior to use. K. pneumoniae and S. aureus were grown and maintained in Luria broth and Luria agar. M. smegmatis cells were grown and maintained in Middlebrook 7H9 broth supplemented with $1 \mathrm{~g} / \mathrm{L}$ casein acid hydrolysate and Middlebrook 7H10 agar supplemented with $1 \mathrm{~g} / \mathrm{L}$ casein acid hydrolysate. C. krusei cells were grown and maintained in Sabouraud dextrose broth and agar.

2.4. Preparation of Plant Extracts. The leaves were washed under running distilled water to remove any dust and grit and then air-dried at room temperature. Leaf powder was prepared manually by hand pounding dry leaves using a wooden pestle and mortar. Phytochemicals from the leaf material were extracted by maceration using the DCM$\mathrm{MeOH}$ extraction and the serial exhaustive extraction methods successively [28].

2.5. Extraction of Phytochemicals with Dichloromethane/ Methanol. Phytochemicals from $1500 \mathrm{~g}$ of powdered P. curatellifolia leaf material was extracted in $4500 \mathrm{~mL}$ of a solution of 50\%:50\% dichloromethane (DCM) and methanol, respectively, for the total extraction. The mixture was left for extraction for 72 hours with constant shaking. The extraction mixture was filtered through cotton wool and then through Whatman No. 1 paper. The leaf debris (residue) was air-dried and stored at room temperature for further extraction. The filtrate was concentrated using a rotary evaporator RII (BUCHI, Labortechnik AG, Switzerland) at $50^{\circ} \mathrm{C}$ and low pressure. The extracts were dried to a 
constant mass under a fan in a fume hood cabinet. Dried extracts were stored in sterile screw cap tubes at $4^{\circ} \mathrm{C}$ until use.

2.6. Serial Exhaustive Extraction. Extraction was done sequentially using different solvents on the leaf debris (residue) from the dichloromethane-methanol mixture (50\% $v / v)$ (DCM-MeOH). The serial exhaustive extraction was done in the following sequence of solvents: hexane, DCM, acetone, ethyl acetate, ethanol, methanol, and water. At each extraction stage, the leaf debris generated after filtration was left to dry in a sterile fume hood; after drying, the debris was used in the subsequent extraction stage. The filtrate was concentrated using a rotary evaporator RII (BUCHI, Labortechnik AG, Switzerland) at $50^{\circ} \mathrm{C}$ and low pressure. The extracts were dried to a constant mass under a fan in a fume hood cabinet. Dried extracts were stored in sterile screw cap tubes at $4^{\circ} \mathrm{C}$ until use. The weight of dry extract obtained was recorded and percentage yield was determined.

$$
\text { extraction yield }(\%)=\frac{\text { weight of dried plant extract }(\mathrm{g})}{\text { weight of dried plant material }(\mathrm{g})} \times 100 \% \text {. }
$$

Crude extracts were collected in vials for further analysis.

\subsection{In Vitro Antimicrobial Activity}

2.7.1. Preparation and Standardization of Inocula. The inoculum of each microbe was prepared by reviving cell from glycerol stocks. Cells for the assay were standardized according to the $0.5 \mathrm{McF}$ arland solution, which is equivalent to $1.5 \times 10^{8} \mathrm{CFU} / \mathrm{mL}$.

2.7.2. INT Colorimetric Assay for Minimum Inhibitory Concentrations (MIC). The inhibitory potential of microbial growth by both the crude extracts and the pure compound was determined by broth microdilution method in 96-well microtiter plates [29]. The MIC assay was conducted using 2(4-iodophenyl)-3-(4-nitrophenyl)-5-phenyl-2H-tetrazolium chloride (INT) colorimetric assay according to Eloff [30] with slight modifications. The assay for minimum inhibitory concentration was conducted according to the plate layout shown in Figure 1. Working concentration of test samples was prepared by dissolving $0.004 \mathrm{~g}$ of the extracts of isolated compound in $1 \mathrm{ml}$ dimethylsulfoxide (DMSO) to make a concentration of $4 \mathrm{mg} / \mathrm{ml}$. Then, $0.5 \mathrm{ml}$ was taken from the working concentration and made up to $10 \mathrm{ml}$ by adding sterile broth media to make a test concentration of $200 \mu \mathrm{g} /$ ml. DMSO was used to prepare the samples was $2.5 \%$. A serial twofold dilution was performed to obtain extract concentrations ranging from 0.4 to $200 \mu \mathrm{g} / \mathrm{mL}$ using sterile broth. Liquid cultures of each test microbe were grown in broth media. These were diluted in fresh broth, and $100 \mu \mathrm{L}$ was applied to the wells of a 96-well plate. In each case, approximately $1.5 \times 10^{8} \mathrm{CFU} / \mathrm{mL}$ of exponentially growing cells were inoculated for each strain. The extracts $(100 \mu \mathrm{L})$ were added to these wells in decreasing concentrations and mixed by pipetting. Each well was further diluted with $100 \mu \mathrm{L}$ microbial inoculum. The final extract concentration in the 96-well plate ranged from 0.2 to $100 \mu \mathrm{g} / \mathrm{mL}$. Cells in wells with unexposed broth were used as the positive control for microbial growth, while wells with plain broth were used as negative cell growth (Figure 1). Cell density of the plate was measured at $590 \mathrm{~nm}$ using a microplate reader (Tecan GENios Pro, Grödig, Austria) prior to incubation. The plate was incubated at $37^{\circ} \mathrm{C}$ for $18 \mathrm{hrs}$. Cell density was measured after incubation. Growth of cells was determined by calculating the difference of the preincubation value from the postincubation value. Data are presented as percentage inhibition of inoculum. Percentage inhibition was obtained using the following equation:

$$
\text { percentage inhibition }(\%)=\frac{\text { positive control value }- \text { sample value }}{\text { positive control value }} \times 100
$$

Following incubation, $50 \mu \mathrm{L}$ of $0.2 \mathrm{mg} / \mathrm{mL}$ INT was added in each well. The plates were incubated for an additional $30 \mathrm{~min}$ at $37^{\circ} \mathrm{C}$. Viable microbes reduced the yellow dye of INT to a pink color. MIC values were defined as the sample concentration that exhibited complete inhibition of bacterial growth, that is, the sample concentration that prevented the color change of INT [30].

\subsubsection{Minimum Bactericidal/Fungicidal Concentration} (MBC/MFC) Determination. The MBC/MFC was determined after MIC assays [31]. The MBC/MFC of the sample was determined by subculturing $50 \mu \mathrm{L}$ of the suspensions from the wells that did not show any growth after incubation during MIC assays on an agar plate. The inoculated agar plates were incubated at $37^{\circ} \mathrm{C}$ for 24 hours before observation. The $\mathrm{MBC} / \mathrm{MFC}$ was defined as the lowest concentration of a sample that completely inhibited the visible microbial growth on the agar plates. Each assay was performed in triplicate.

2.8. Chromatographic Separation of Extracts. Active extracts against at least one of the test organisms were selected and combined. Combined extracts were fractionated using the gradient elution column chromatography. In this study, the methanol extract, DCM:MeOH extract, ethanol extract, and hexane extract were selected for chromatographic separation.

\subsubsection{Gradient Elution Column Chromatography.} Selected extracts were combined and adsorbed on equal mass of silica (70 $\mathrm{g}$ of silica, 60-120 mesh) to make a loading 


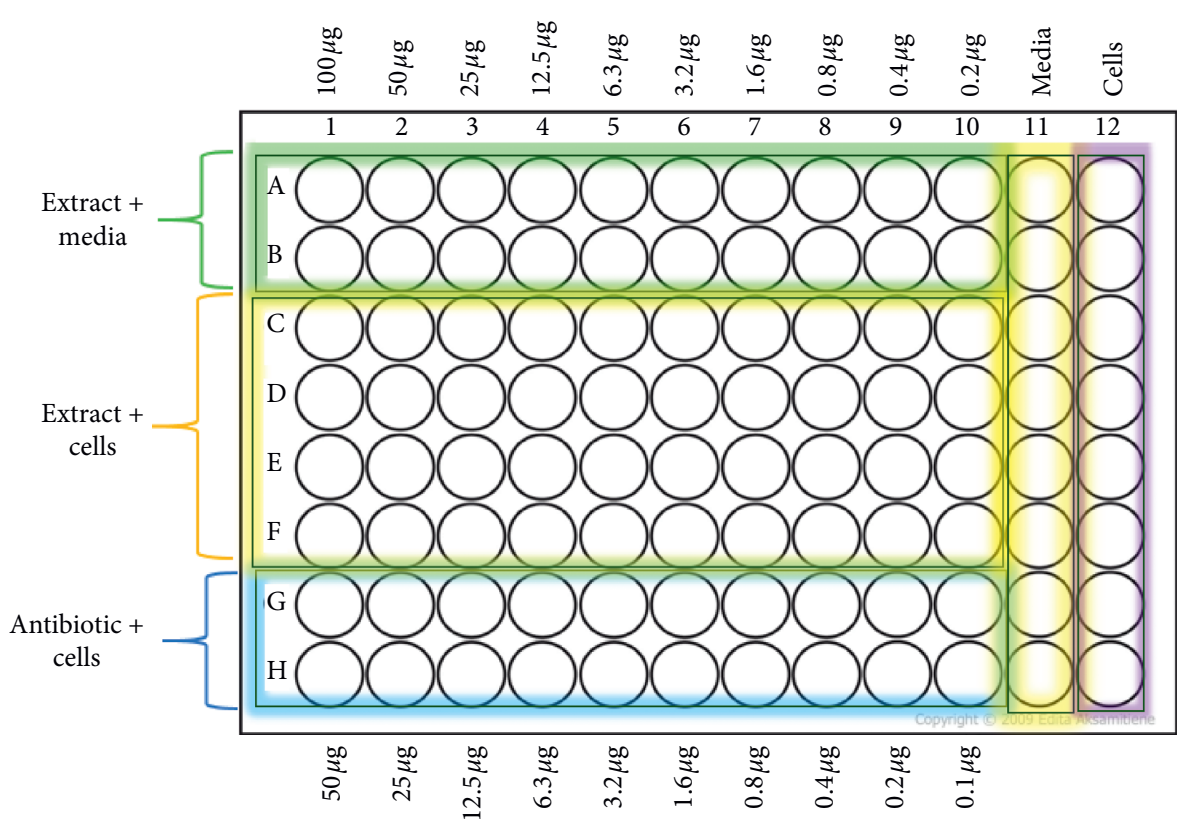

Figure 1: Plate setup for 2-(4-iodophenyl)-3-(4-nitrophenyl)-5-phenyl-2H-tetrazolium chloride (INT) colorimetric assay for minimum inhibitory concentrations (MIC). The "cells" column is the positive control for microbial growth (cells were inoculated in untreated broth media). The "media" column is the negative control for cell growth (wells contained uninoculated broth media). The "antibiotic + cells" rows are the antibiotic/antifungal positive control (cells were inoculated in wells with decreasing standard antimicrobial/antifungal concentration). The "extract + cells" rows are the test wells (cells were inoculated in wells with decreasing extracts concentrations).

sample. The sample was packed on a silica gel column, and the gradient elution method was used to run the column. The column was first eluted with $n$-hexane as the mobile phase, and the polarity of the mobile phase was increased by gradually adding $2.5 \%$ of ethyl acetate increments. After reaching $100 \%$ ethyl acetate, the polarity was further increased by gradually adding $2.5 \%$ methanol. Volumes of $250 \mathrm{~mL}$ fractions of the eluate were collected during the process. A total of 428 fractions were obtained from the column chromatography, and each fraction was concentrated using a rotary evaporator RII (BUCHI, Labortechnik AG, Switzerland). The fractions were dried to a constant mass under a fan in a fume hood cabinet. All fractions were stored in sterile screw top tubes at room temperature.

\subsubsection{TLC Profiling of Chromatographic Fractions.} Concentrated fractions were subjected to thin layer chromatography (on aluminium plate coated with Mercy, silica gel 60 F254). TLC plates were developed for each fraction in a saturated tank with a mobile phase of slightly higher polarity than used in column chromatography to elute the fraction. For example, fractions eluted in $100 \%$ hexane were developed in 97.5:2.5 (HEX:EA) solution. Developed chromatograms were located by observation under short and long ultraviolet light (short UV and long $\mathrm{UV}$ at $254 \mathrm{~nm}$ and $360 \mathrm{~nm}$, respectively), then sprayed with $10 \% \mathrm{w} / v$ sulphuric acid, and dried at $100^{\circ} \mathrm{C}$. Fractions showing similar profile were pooled into the same pool. Pooled fractions were dried in glass vials and their yields determined. Pooled fractions were then kept at room temperature for further analysis.
2.9. Purification of Compounds Using Preparative TLC. Fractions showing the best TLC separation as well as sufficient yield were selected for further purification of single compounds using the preparative TLC. In this case, pools 7 and 10 were selected for the isolation of single compounds. Preparative TLC was made by absorbing the extracts on $2 \mathrm{~mm}$ layer of silica Type $\mathrm{G}$ with $13 \%$ calcium sulphate on $20 \times 20 \mathrm{~cm}$ glass plate. The plate was activated by heating in oven at $60^{\circ} \mathrm{C}$ for 30 minutes prior to use. The selected pools were combined, dissolved in chloroform, and then loaded on the activated TLC plate. The plate was allowed to develop in a chloroform-saturated tank. Once developed, the separated chromatograms were observed under UV light at $254 \mathrm{~nm}$ using a UV lamp in a UV-viewing cabinet. At least four chromatograms of different colors were separated. Silica at the position showing a single isolated chromatogram on the plate was scraped off using a metal spatula blade. The chromatogram content on the scraped silica was eluted using chloroform through a Whatman No. 1 filter paper into four different glass vials. The eluent was then evaporated at room temperature and then stored as solids in the vials. The crystallized solids in the vials were further analyzed for purity using TLC with chloroform as the mobile phase. The solids that gave a single TLC chromatogram confirmed the purity of the isolated compound. Using TLC, only one compound out of four was confirmed to be a pure compound. Antimicrobial evaluation of the pure compound was determined against the test microbes. NMR analyses and determination of the mass of the isolated compound were carried out.

2.10. NMR Analyses and Determination of the Mass of the Isolated Compound. The ${ }^{1} \mathrm{H}$ NMR spectra were recorded at $400 \mathrm{MHz}$ and ${ }^{13} \mathrm{C}$ NMR spectra at $100 \mathrm{MHz}$. The chemical 
shifts for ${ }^{1} \mathrm{H}$ NMR and ${ }^{13} \mathrm{C}$ NMR were referenced to TMS via residual solvent signals $\left({ }^{1} \mathrm{H}, \mathrm{CDCl}_{3}\right.$ at $7.26 \mathrm{ppm} ;{ }^{13} \mathrm{C}, \mathrm{CDCl} 3$ at $77.36 \mathrm{ppm} ;{ }^{1} \mathrm{H}, \mathrm{DMSO}-d_{6}$ at $2.45 \mathrm{ppm} ;{ }^{13} \mathrm{C}$, DMSO- $d_{6}$ at $39.43 \mathrm{ppm} ;{ }^{1} \mathrm{H}, \mathrm{CD}_{3} \mathrm{OD}$ at $3.31 \mathrm{ppm} ;{ }^{13} \mathrm{C}, \mathrm{CD}_{3} \mathrm{OD}$ at $49.0 \mathrm{ppm})$. The $2 \mathrm{D}$ NMR experiments were run using standard pulse sequences. Molecular formulae were determined by electrospray ionization with a 7-T hybrid ion trap and a TOF detector running in positive or negative mode. $\beta$-Sitosterol (Figure 2) was identified as one of the pure compounds, and its effects on the test organisms were evaluated.

\subsection{Biocidal Activity Assays of the Most Active Compounds on} Mendy Fabric. Biocidal evaluation of the purified compounds was done on the Mendy fabric, which is the material used to make uniforms for nurses in Zimbabwe. The biocidal evaluation was done using a simple and rapid method for optical visualization and quantification of bacteria on fabrics using the INT dye, by Stiefel et al. [10] with some modifications. Absorbance measurements for the biocidal activity assay were done using a Shimadzu UV/VIS UV-1601 spectrophotometer (Shimadzu, Kyoto, Japan). Standard curves to correlate the staining intensity with the numbers of microbial cells were first generated. The standard curves were used to determine the number of bacterial and fungal cells left after the microbial contaminated fabric was treated with the isolated compound.

To generate the standard curves, $100 \mu \mathrm{L}$ microbial culture of different concentrations $\left(\mathrm{OD}_{600}: 0,0.125,0.25,0.375\right.$, and 0.5 ) was directly applied to the fabric samples in 6-well plates. Samples were incubated for an hour at $37^{\circ} \mathrm{C}$. After incubation, $1 \mathrm{~mL}$ of media and $0.2 \mathrm{mg} / \mathrm{ml} 2$-(4-iodophenyl)3-(4-nitrophenyl)-5-phenyl-2H-tetrazolium chloride (INT) was added to each fabric (staining with tetrazolium salt). The sample was incubated for 30 minutes at $37^{\circ} \mathrm{C}$ and with shaking at $40 \mathrm{rpm}$. After incubation, the liquid was removed, and $1 \mathrm{~mL}$ dimethyl sulfoxide (DMSO) was added to each well. The dye was removed by pipetting the mixture several times onto the fabric until a homogenous color was obtained. Absorption of the eluate was measured at $490 \mathrm{~nm}$ using DMSO as a blank. As a background control the different fabrics were treated in the same way using media without bacteria.

To correlate $\mathrm{OD}_{600}$ values of the applied culture with cell numbers, colony forming units (CFU) were determined at the same time point as the staining of bacterial culture. The same bacterial solutions as added to fabrics were also incubated for 1 hour at $37^{\circ} \mathrm{C}$ and $80 \mathrm{rpm}$. After 1 hour, the bacterial culture was used to determine cell numbers by plating a 1:10 dilution series on agar. The CFU of appropriate dilutions were counted after 1 day, and the exact cell numbers corresponding to the applied culture were determined. The bacterial culture with an $\mathrm{OD}_{600}$ value of 0.5 corresponded to about $3.15 \times 10^{10}$ bacteria per square centimetre of fabric for M. smegmatis cells and $5.6 \times 10^{8}$ fungal cells per square centimetre for C. krusei. All the standard curves were generated using GraphPad Prism (Version 5.03, GraphPad Software Inc., San Diego, California, USA).
To evaluate the biocidal activities of the compounds on the Mendy fabric, $100 \mu \mathrm{L}$ of the microbial culture with an $\mathrm{OD}_{600}$ of 0.5 in broth media was directly applied to the fabric samples in 6-well plates and incubated for 1 hour at $37^{\circ} \mathrm{C}$. After incubation, $100 \mu \mathrm{L}$ of $(200 \mu \mathrm{g} / \mathrm{mL})$ test compound was directly applied to the fabric samples in the 6-well plates and incubated for 30 minutes at $37^{\circ} \mathrm{C}$. Concentrations of $100 \mu \mathrm{g} /$ $\mathrm{mL}$ and $50 \mu \mathrm{g} / \mathrm{mL}$ of chlorhexidine digluconate were applied to pieces of the same fabric in different wells as the biocide positive control. After incubation, $1 \mathrm{~mL}$ growth medium containing $0.2 \mathrm{mg} / \mathrm{mL}$ INT was added to the fabric without removing unbound bacteria and incubated for 30 minutes at $37^{\circ} \mathrm{C}$ and $40 \mathrm{rpm}$. The dye was eluted from the fabric using $1 \mathrm{~mL}$ DMSO and pooled with the supernatant, in order not to lose the unbound bacteria. Staining intensity was quantified by measuring absorbance at $490 \mathrm{~nm}$ using a Stat Fax 2100 microplate reader (Awareness Technologies Inc., Westport, USA). For background control, media without bacteria were used during incubation. The number of viable cells that remained on the fabric was quantified by comparing the measured signal intensity to the standard curve.

2.12. Statistical Analysis. Statistically significant differences between the mean of the controls and the tests were analyzed using one-way ANOVA with Dunnett's multiple comparison posttest. Enzyme kinetics were analyzed with linear regression using GraphPad Prism (Version 5.03, GraphPad Software Inc., San Diego, California, USA).

\section{Results}

3.1. Extraction Yields of the Plant Extracts. The highest yield, $3.53 \%$, was obtained from extraction of $P$. curatellifolia leaves with the dichloromethane (DCM) and methanol, while the least yield, $0.23 \%$, was from the hexane extraction (Table 1 ).

\subsection{In Vitro Antimicrobial Activity of the Extracts.} Evaluation of the antimicrobial activities of the extracts against the four test organisms was done using the INT colorimetric assay for minimum inhibitory concentrations. The study has shown that all the extracts used in the study exhibited varying degrees of antimicrobial activity against all the microorganisms tested (Table 2). The DCM-methanol extract had the highest activity against $S$. aureus, reducing cell growth by $90 \%$ after incubation. However, the ethyl acetate extract had the least activity of only $3.6 \%$ against S. aureus (Figure 3(a)). There was no complete inhibition of growth for S. aureus and K. pneumoniae by any of the crude extracts even at the highest concentration, $100 \mu \mathrm{g} / \mathrm{mL}$, that was tested (Figures 3(a) and 3(b)). However, the DCMmethanol extract had the highest activity, $75 \%$, against the $K$. pneumoniae, while the water extract had the lowest activity, only 26.9\%, after incubation (Figure 3(b)). M. smegmatis was more susceptible to all the P. curatellifolia extracts compared to other test microbes (Table 2). The ethanol and methanol extracts had the highest activity of MIC, $25 \mu \mathrm{g} / \mathrm{mL}$, against the M. smegmatis, followed by the DCM-methanol and the acetone extract which had MIC of 


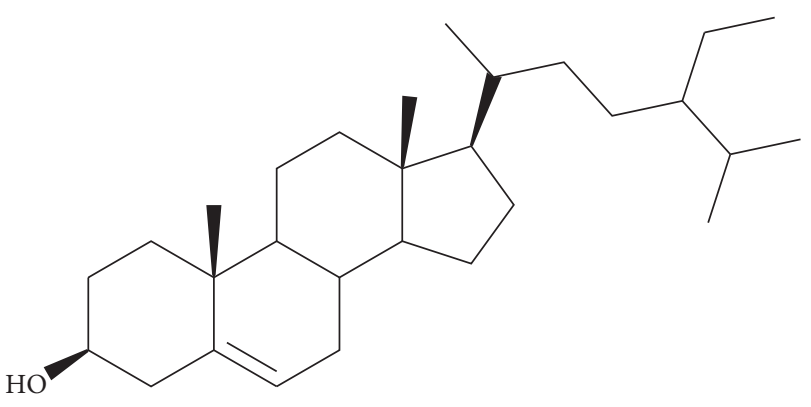

FIGURE 2: Structure of $\beta$-sitosterol.

Table 1: Extraction yield of the P. curatellifolia leaves.

\begin{tabular}{lcc}
\hline Extraction solvent & $\begin{array}{c}\text { Extract mass } \\
(\mathrm{g})\end{array}$ & $\begin{array}{c}\text { Percentage yield } \\
(\%)\end{array}$ \\
\hline $\begin{array}{l}\text { Dichloromethane: } \\
\text { methanol }\end{array}$ & 53.0 & 3.53 \\
Hexane & 3.25 & 0.23 \\
Ethyl acetate & 5.70 & 0.41 \\
Ethanol & 32.5 & 2.46 \\
Methanol & 43.0 & 3.31 \\
Water & 30.0 & 3.0 \\
\hline
\end{tabular}

TABle 2: Antimicrobial activities of the extracts on the test organisms expressed as \% inhibition at $100(\mu \mathrm{g} / \mathrm{mL}) / \mathrm{MIC}(\mu \mathrm{g} / \mathrm{mL}) /$ $\operatorname{MBC}(\mu \mathrm{g} / \mathrm{mL})$.

\begin{tabular}{|c|c|c|c|c|}
\hline Extracts & S. aureus & K. pneumoniae & M. smegmatis & C. krusei \\
\hline $\begin{array}{l}\text { DCM: } \\
\text { methanol }\end{array}$ & 89.9/-/- & $74.8 /-/-$ & $100 / 50 / 50$ & $0 /-/-$ \\
\hline Hexane & $54.9 /-/-$ & $37.5 /-/-$ & $55.3 /-/-$ & $\begin{array}{c}100 / 25 / \\
50\end{array}$ \\
\hline $\begin{array}{l}\text { Ethyl } \\
\text { acetate }\end{array}$ & $3.6 /-/-$ & $54.2 /-/-$ & $70.3 /-/-$ & $16.9 /-/-$ \\
\hline Acetone & $50.1 /-/-$ & $47.9 /-/-$ & $100 / 50 /-$ & $0 /-/-$ \\
\hline Ethanol & $51.8 /-/-$ & $50.7 /-/-$ & $100 / 25 /-$ & $33.6 /-/-$ \\
\hline Methanol & $81.5 /-/-$ & $52.5 /-/-$ & $100 / 25 / 100$ & $21.9 /-/-$ \\
\hline Water & $50.2 /-/-$ & $26.9 /-/-$ & $75.3 /-/-$ & $64 /-/-$ \\
\hline
\end{tabular}

MIC: minimum inhibitory contraction. "-" means that MIC/MBC/MFC was greater than $100 \mu \mathrm{g} / \mathrm{mL}$. "0" means no inhibition.

$50 \mu \mathrm{g} / \mathrm{mL}$ each on the same cells (Figure 3(c)). The DCM$\mathrm{MeOH}$ had an $\mathrm{MBC}$ value of $50 \mu \mathrm{g} / \mathrm{mL}$ while the methanol extract had an MBC value of $100 \mu \mathrm{g} / \mathrm{mL}$ against M. smegmatis (Table 2). Only the hexane extract and water extract were able to inhibit the growth of $C$. krusei cells by more than $50 \%$ at a concentration of $100 \mu \mathrm{g} / \mathrm{mL}$ after incubation (Figure 3(d)). The DCM-methanol and the acetone extract completely failed to inhibit growth of C. krusei (Figure 3(d)). The hexane extract was the most effective in inhibiting growth of C. krusei with an MIC value of $25 \mu \mathrm{g} /$ $\mathrm{mL}$ after incubation (Figure 3(d)), but no extracts exhibited MFC against C. krusei (Table 2).

3.3. Chromatographic Separation of Extracts. The extracts that had potent antimicrobial activity are as follows: DCMmethanol extract, hexane extract, ethanol extract, and ethanol extract by inhibiting growth of at least one test organism (Table 2) were selected for chromatographic separation. Selected extracts were combined and fractionated using gradient elution column chromatography. A total of 43 distinct pools were obtained from 428 fractions. The pools were numbered from 1 to 43 . Pools 7 and 10 (Figure 4) were observed to exhibit better separation of chromatogram on TLC plate. Pools 7 and 10 were selected for further separation of single compounds using preparative TLC. At least four chromatograms with different colors, red, white, dark red, and purple, were obtained. The chromatograms were assigned code names Pc4963r, Pc4962w, Pc6978o, and Pc6978p, respectively, for identification (Figure 5).

The migrating chromatograms were isolated by scrapping off silica containing the targeted chromatograms from the glass plate. The composition of separated chromatograms on the scraped silica was eluted using chloroform through the Whatman No. 1 filter paper into different glass vials. The purity of each isolated chromatogram was determined using TLC. At least four compounds were obtained after elution of the four chromatograms from the silica. The four compounds showed different colors, red, white, orange, and purple, with Rf values of $0.74,0.40,0.57$, and 0.38 , respectively (Figure 6). The compounds were given code names Pc4963r, Pc4962w, Pc6978o, and Pc6978p (Figure 6). Only the contents of Pc6978p were shown to contain a single compound by showing a single spot on the TLC plate (Figure 6). The structure of the pure isolated Pc6978p was determined to be $\beta$-sitosterol (Figure 2) by NMR as confirmed by the ${ }^{1} \mathrm{H}$ NMR $(\mathrm{CDC} 13,500 \mathrm{MHz})$ and ${ }^{13} \mathrm{C}$ NMR $\left(\mathrm{CDCl}_{3}, 125 \mathrm{MHz}\right)$ spectrum of Pc6978p (Figure 7). The compounds showing more than one spot on the TLC were stored in glass vials for further analysis on a later stage.

3.4. In Vitro Bioactivities of the Purified Compounds. Compounds Pc4963r, Pc4962w, and Pc6978p were selected for the evaluation of antimicrobial activities against the test organisms. Compound Pc6978o was left out due to very low yield, lower than $3 \mathrm{mg}$ (Table 2). Figure 8 shows a graph of the antimicrobial activities of Pc4963r, Pc4962w, and Pc6978p at concentration of $100 \mu \mathrm{g} / \mathrm{mL}$ against test cells. The cell densities correspond to the growth of cells after incubation at $37^{\circ} \mathrm{C}$ overnight. Compound Pc6978p showed the highest reduction effects on the growth of $S$. aureus cells with a percentage antibacterial activity of $75.3 \%$, followed by Pc4963r which had a percentage activity of $71.1 \%$ (Figure 8(a)). Compared to the other two isolated compounds, Pc4962w had the least antibacterial activity against S. aureus, with a percentage activity of 50.5\% (Figure 8(a)). However, statistical analysis using the one-way ANOVA (where $P<0.05$ ) has shown that all compounds had statistically significant reduction effects on growth of $S$. aureus (Figure 8(a)). Data analysis showed that all the compounds significantly reduced the growth of $K$. pneumoniae (Figure 8(b)). However, compared to the other two isolated compounds, Pc6978p had the least antibacterial activity against K. pneumoniae, with a percentage activity of $39 \%$ (Figure 8(b)). Compound Pc4962w showed the highest reduction effects on the growth of $K$. pneumoniae cells with a 


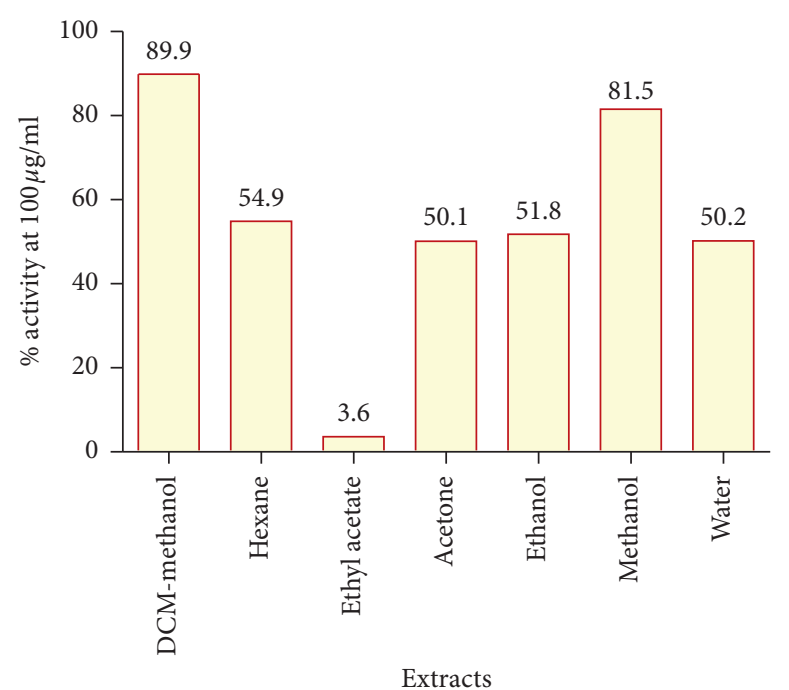

(a)

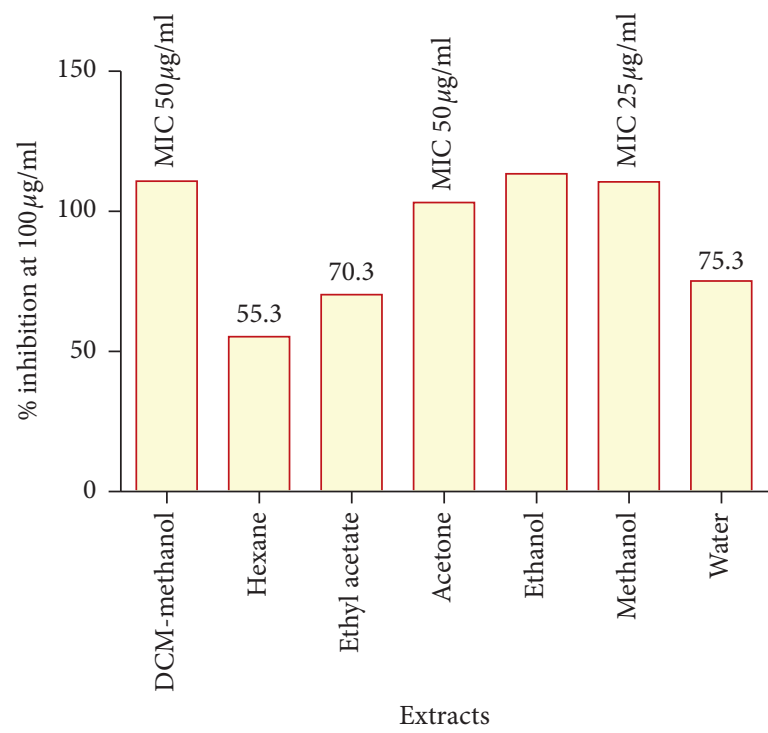

(c)

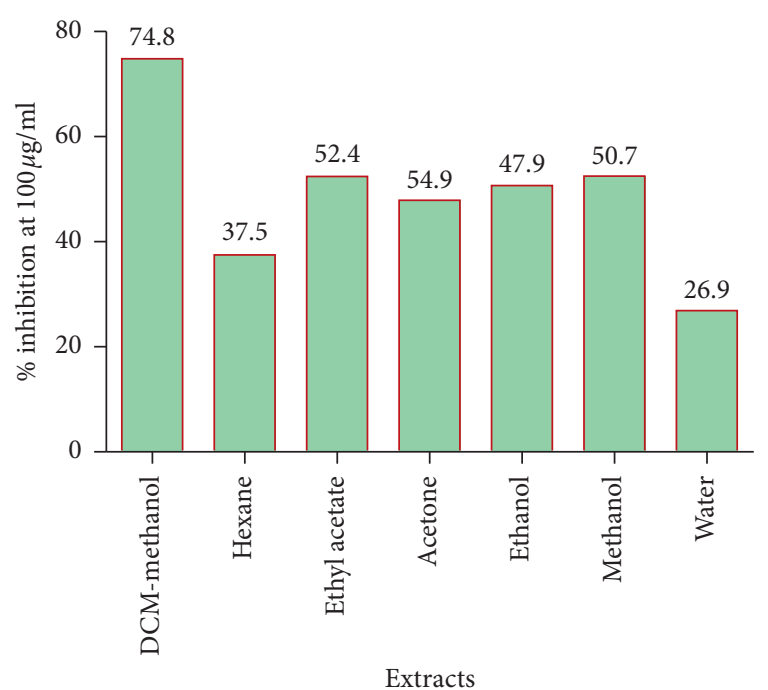

(b)

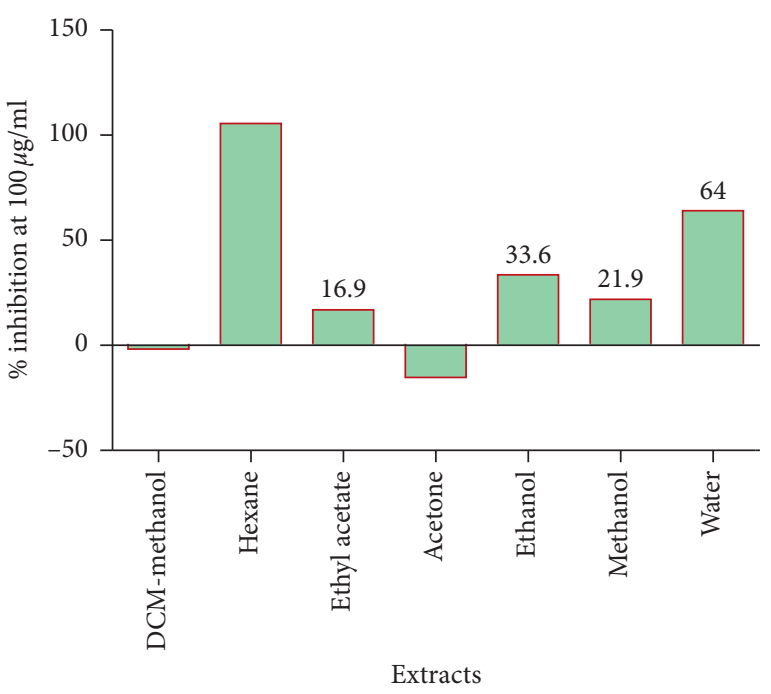

(d)

Figure 3: Percentage inhibition of the crude P. curatellifolia extracts at $100 \mu \mathrm{g} / \mathrm{mL}$ on the growth of S. aureus (a), K. pneumoniae (b), M. smegmatis (c), and C. krusei cells (d).

percentage antibacterial activity of $51 \%$, followed by Pc4963r which had a percentage activity of $44 \%$ (Figure $8(\mathrm{~b})$ ). Compound Pc6978p showed the highest reduction effects on the growth of $M$. smegmatis cells with a percentage antibacterial activity of $97.9 \%$, followed by Pc4963r which had a percentage activity of $46.8 \%$ (Figure $8(\mathrm{c})$ ). Compared to the other two isolated compounds, Pc4962w had the least antibacterial activity against $M$. smegmatis with the percentage activity of $31.9 \%$ (Figure $8(\mathrm{c})$ ). However, statistical analysis using the one-way ANOVA (where $P<0.05$ ) has shown that all the compounds significantly reduced the growth of the M. smegmatis (Figure 8(c)). The antifungal activities of Pc4963r, Pc4962w, and Pc6978p at concentration of $100 \mu \mathrm{g} /$ $\mathrm{mL}$ against $C$. krusei cells were investigated. The graph in Figure 8(d) shows that all the three isolated compounds completely inhibit the growth of C. krusei cells.
3.5. Biocidal Activity Assays of $\beta$-Sitosterol (Pc6978p) on Mendy Fabric. Pc6978p had the highest activity against C. krusei and M. smegmatis. Therefore, biocidal activity of compound Pc6978p was evaluated against M. smegmatis and C. krusei. Standard curves were first generated by adding different concentrations of cell on different pieces of fabric; the increase in color intensity corresponded to the increasing number of cells (Figure 9). A typical layout of the fabric used to generate the standard curves is shown in Figure 9(a). The color intensity of the dye on fabric was increasing from $\mathrm{OD}_{490}$ 0 to $\mathrm{OD}_{490} 0.5$ indicating the increasing cell numbers attached to different pieces of Mendy fabric. Figures 9(b) and 9(c) show standard curves of the INT staining intensity relative to the C. krusei and M. smegmatis cell numbers, respectively.

At a concentration of $100 \mu \mathrm{g} / \mathrm{mL}$, compound Pc6978p had $83 \%$ biocidal activity against $C$. krusei attached to the 


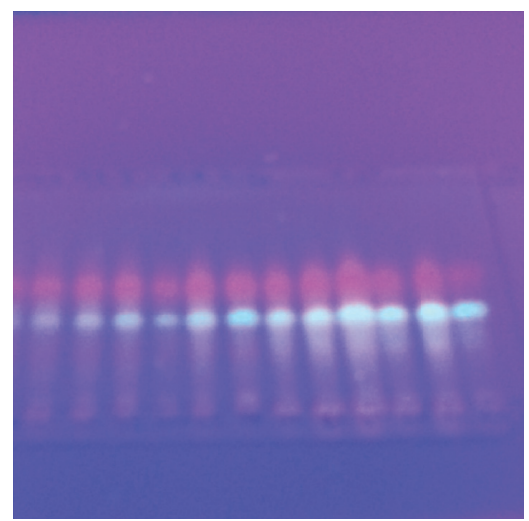

(a)

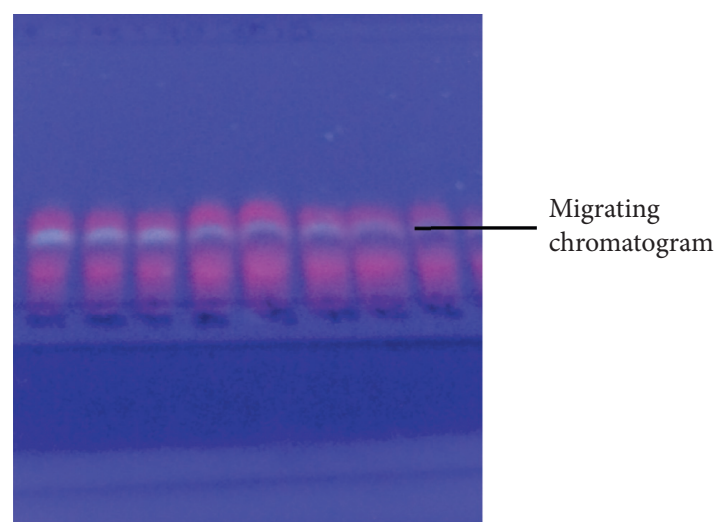

(b)

FIgURE 4: TCL chromatogram showing similar fractions constituting pool 7 (a) and pool 10 (b).

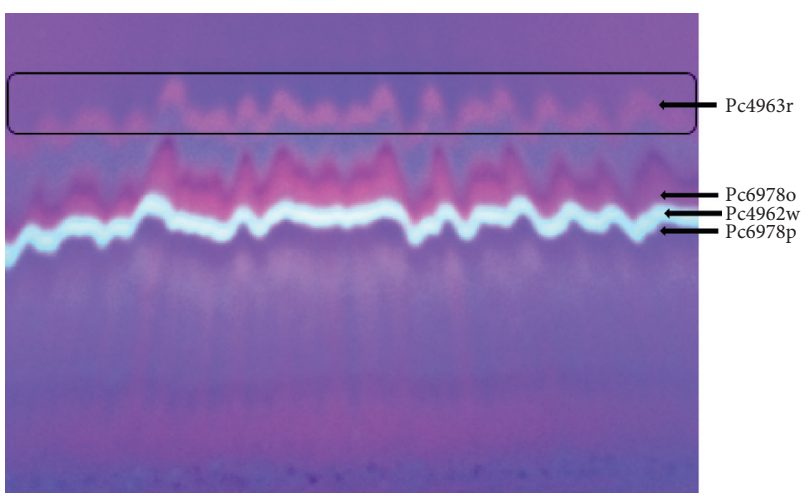

FIgURE 5: Preparative TLC chromatogram. The chromatogram shows that at least four chromatograms (Pc4963r, Pc4962w, Pc6978p, and Pc6978o) migrated to different positions as visualized under UV.

Mendy fabric (Figure 10(a)). The compound removed and killed about $4.45 \times 10^{8} \mathrm{C}$. krusei cells per $\mathrm{cm}^{2}$ of Mendy fabric after 30 minutes of incubation. The positive control chlorhexidine digluconate $50 \mu \mathrm{g} / \mathrm{mL}$ and $100 \mu \mathrm{g} / \mathrm{mL}$ had $59 \%$ and $79 \%$ biocidal activity on C. krusei attached to the Mendy fabric (Figure 10). Statistical analysis using the one-way ANOVA showed that there was no difference between the biocidal activities of the positive control chlorhexidine digluconate at $100 \mu \mathrm{g} / \mathrm{mL}$ and the compound Pc6978p. Pc6978p did not have significant biocidal activity, only producing $5.8 \%$ cell reduction against M. smegmatis attached to the Mendy fabric (Figure 10(b)).

However, the compound has been shown have biocidal activity of around $1.9 \times 10^{9} \mathrm{M}$. smegmatis cells attached to 1 $\mathrm{cm}^{2}$ of Mendy textile after 30 minutes of incubation. The positive control chlorhexidine $50 \mu \mathrm{g} / \mathrm{mL}$ and $100 \mu \mathrm{g} / \mathrm{mL}$ had $64.7 \%$ and $90.1 \%$ biocidal activity on $K$. pneumoniae cells attached to the Mendy textile in only 30 minutes, which was significantly different from the activity of the compound Pc6978p (Figure 10(b)).

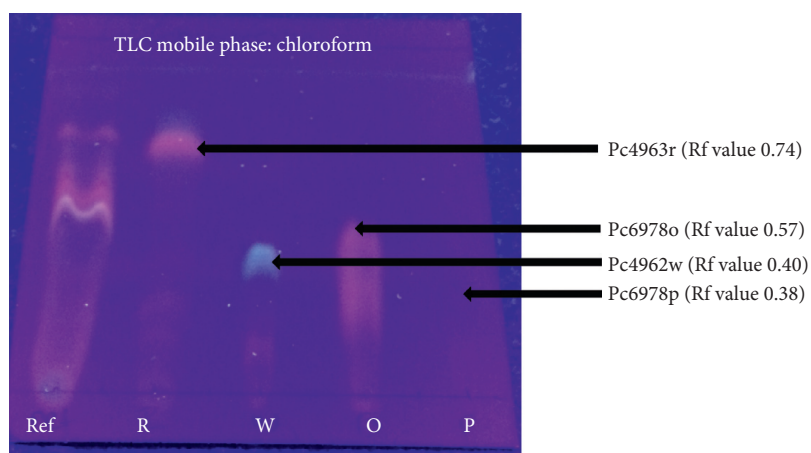

Figure 6: TLC plate showing the four isolated chromatograms as visualized under UV $254 \mathrm{~nm}$. Spot labeled R is the chromatogram Pc4963r. W is the chromatogram Pc4962w. Spot O is the chromatogram Pc6978o. Spot labeled P is the chromatogram Pc6978p. Spot labeled Rf represents unpurified pools as a reference. Chloroform was the mobile phase.

3.6. Structure Determination of the Isolated Compound. The structure of the compound Pc6978p was confirmed by the nuclear magnetic resonance (NMR) spectroscopy to be $\beta$-sitosterol (Figure 2) [31, 32]. The following are the spectroscopic characteristics of the compound Pc6978p: ${ }^{1} \mathrm{H}$ NMR $\left(500 \mathrm{MHz}, \mathrm{CDCl}_{3}\right) \delta: 5.35(1 \mathrm{H}$, brq $, J=1.5,2.0,3.0 \mathrm{~Hz}$, H-6), 3.52 (1H, $m, \mathrm{H}-3 \alpha), 1.01$ (3H, s, Me-19), $0.92(3 \mathrm{H}, d$, $J=6.5 \mathrm{~Hz}, \mathrm{Me}-21), 0.86(3 \mathrm{H}, t, J=5.0 \mathrm{~Hz}, \mathrm{Me}-29), 0.84(3 \mathrm{H}$, $d, J=2.0 \mathrm{~Hz}, \mathrm{Me}-26), 0.83(3 \mathrm{H}, d, J=4.0 \mathrm{~Hz}, \mathrm{Me}-27), 0.68$ (3H, s, Me-18) (Figure 7(a)).

${ }^{13} \mathrm{C}-\mathrm{NMR}\left(100 \mathrm{MHz}, \mathrm{CDCl}_{3}\right) \delta: 140.75(s, \mathrm{C}-5), 121.70$ (d, C-6), 71.81 ( $d, \mathrm{C}-3), 56.78$ (d, C-14), 56.07 (d, C-17), 50.15 (d, C-9), 45.85 ( $d, \mathrm{C}-24), 42.33$ ( $s, \mathrm{C}-13), 42.32(t, \mathrm{C}-4), 39.78$ $(t, \mathrm{C}-12), 37.26(t, \mathrm{C}-1), 36.51(s, \mathrm{C}-10), 36.15$ ( $d, \mathrm{C}-20), 33.96$ $(t, \mathrm{C}-22), 31.92(t, \mathrm{C}-7), 31.88(d, \mathrm{C}-8), 31.68(t, \mathrm{C}-2), 29.17$ $(d, \mathrm{C}-25), 28.24(t, \mathrm{C}-16), 26.10(t, \mathrm{C}-23), 24.30(t, \mathrm{C}-15)$, $23.08(t, \mathrm{C}-28), 21.09(t, \mathrm{C}-11), 19.81(q, \mathrm{C}-26), 19.39(q$, C-19), 19.04 ( $q, \mathrm{C}-27), 18.78$ ( $q, \mathrm{C}-21), 11.98$ ( $q, \mathrm{C}-18), 11.86$ ( $q$, C-29) (Figure 7(b)). HRESI-MS: $m / z 414.4031$ (calcd. for $\left.\mathrm{C}_{29} \mathrm{H}_{50} \mathrm{O}, 414.3861\right) . \mathrm{mp}=137.8-138.7^{\circ} \mathrm{C}$. 


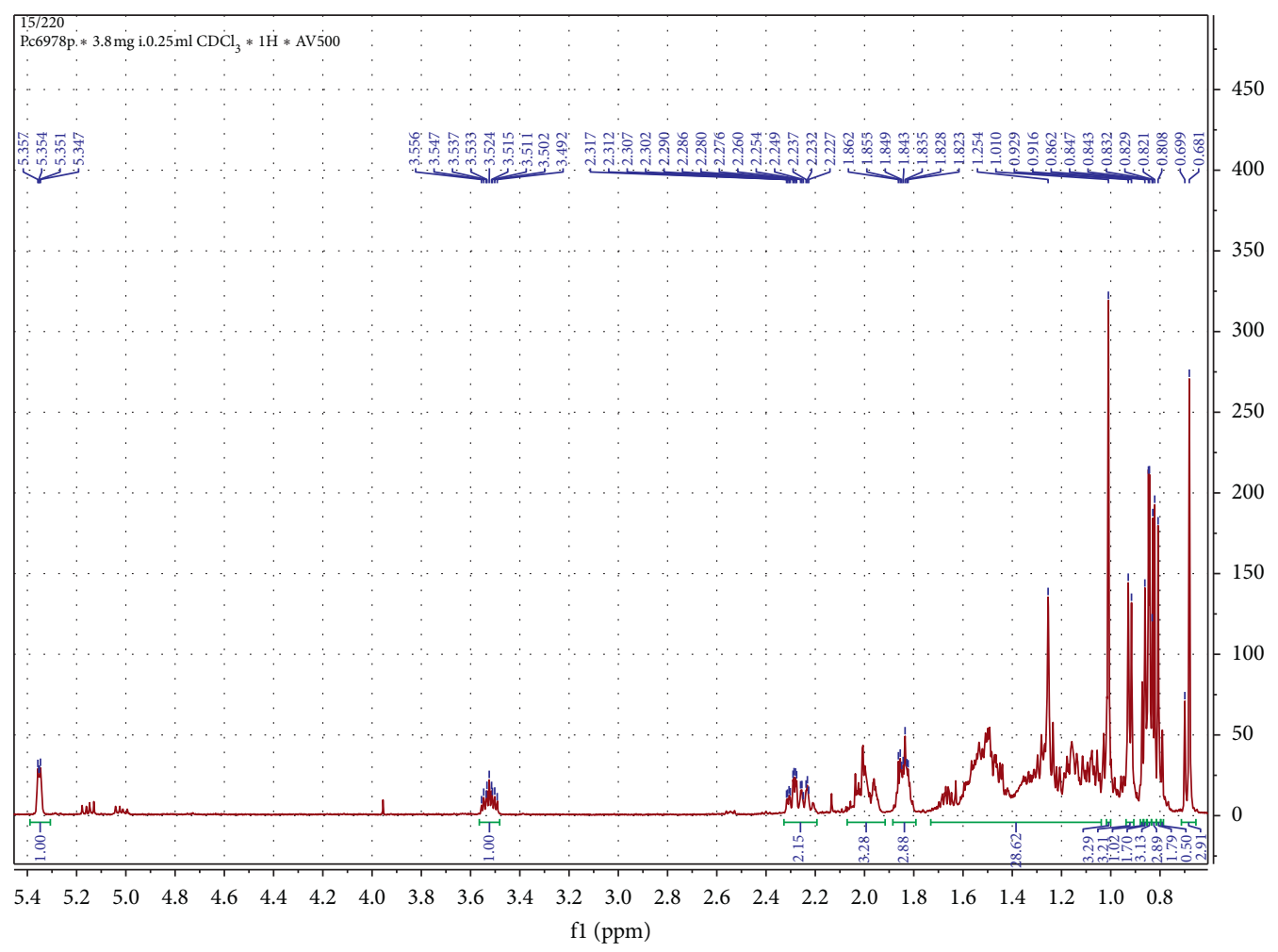

(a)

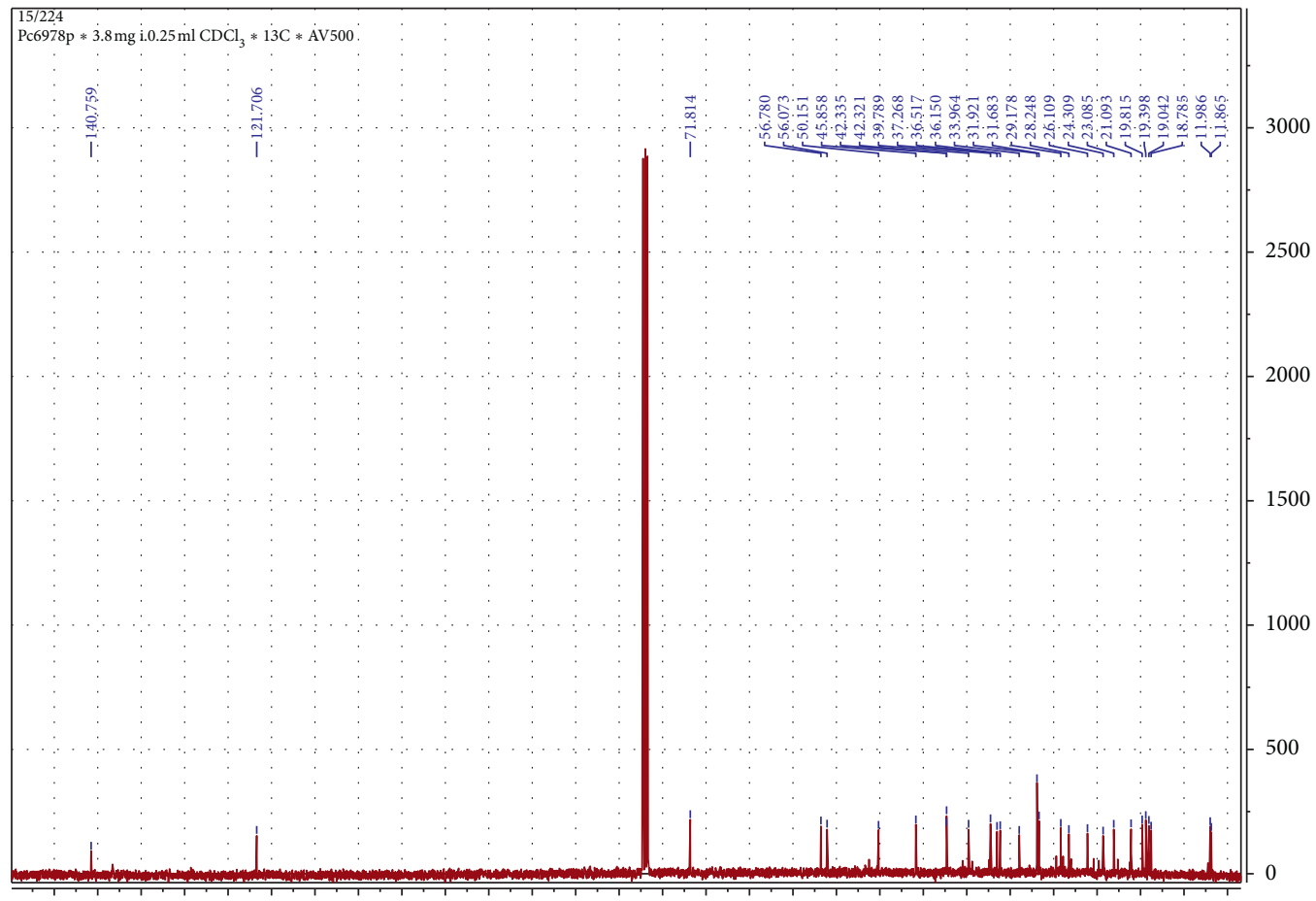

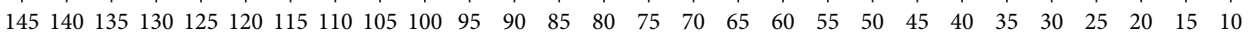
fl $(\mathrm{ppm})$

(b)

Figure 7: ${ }^{1} \mathrm{H}$ NMR $\left(\mathrm{CDCl}_{3}, 500 \mathrm{MHz}\right)$ spectrum of Pc6978p (a) and ${ }^{13} \mathrm{C}$ NMR $\left(\mathrm{CDCl}_{3}, 125 \mathrm{MHz}\right)$ spectrum of Pc6978p (b). 


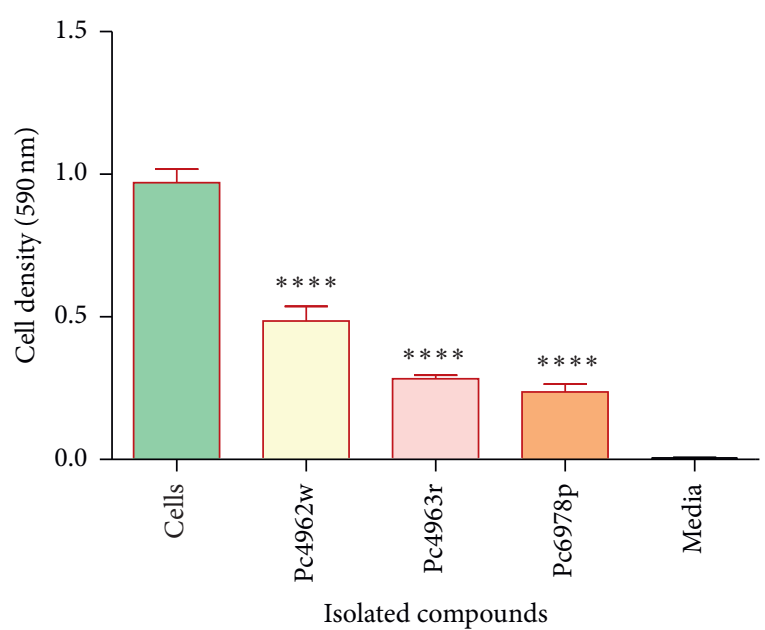

(a)

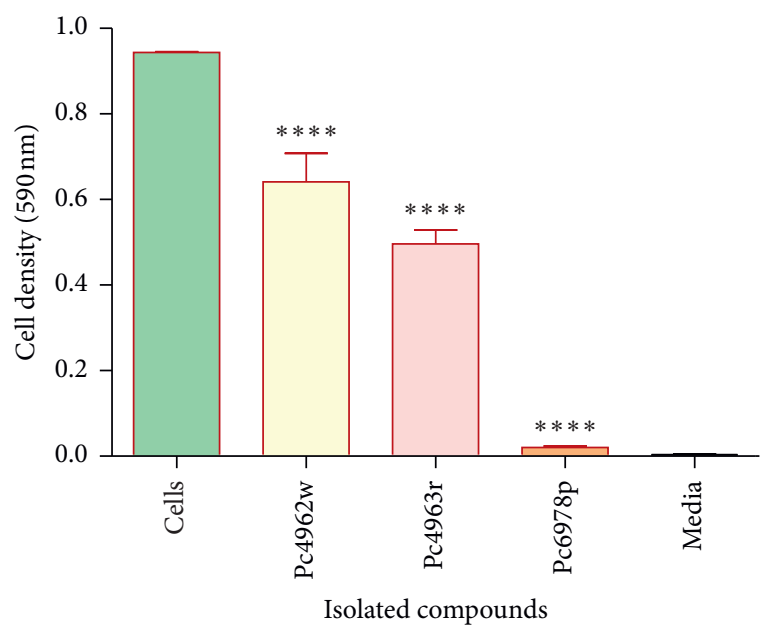

(c)

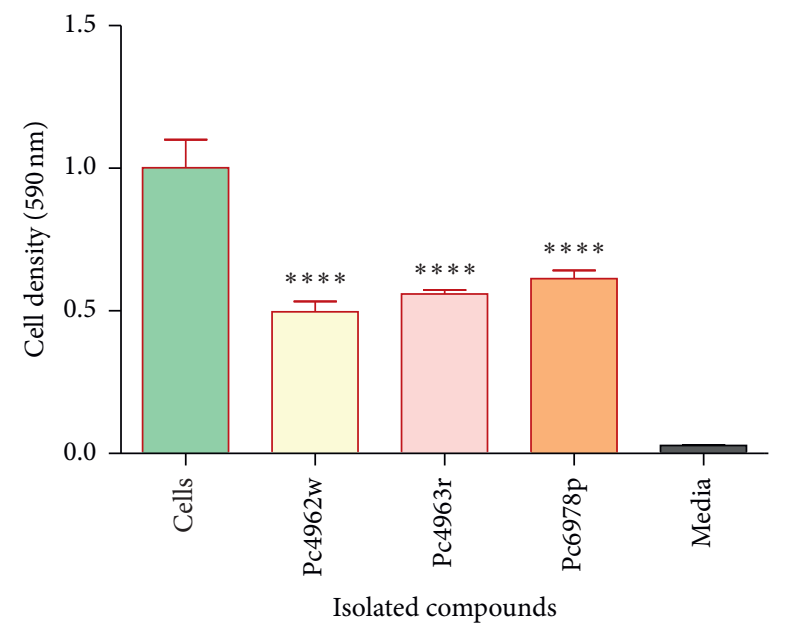

(b)

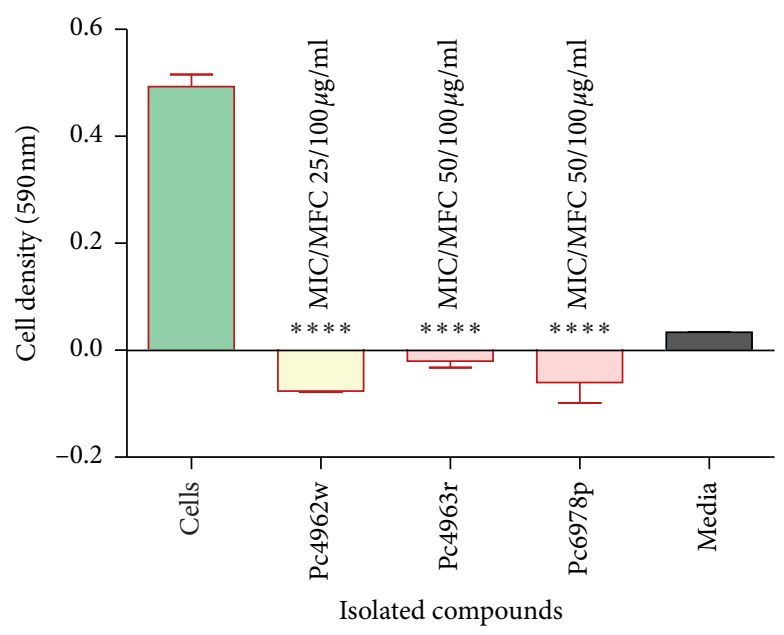

(d)

FIGURE 8: In vitro antibacterial effects of the isolated compounds at a concentration of $100 \mu \mathrm{g} / \mathrm{mL}$ against S. aureus (a), K. pneumoniae (b), M. smegmatis (c), and C. krusei (d). "Media" column is the negative control showing no cell growth. "Cells" column is the positive control for cell growth. Error bars represent the standard deviation from mean $(n=4)$. The asterisk $(*)$ indicates the significant difference from the positive control using statistical one-way ANOVA (where $* P<0.05, * * P<0.01, * * * P<0.001, * * * * P<0.0001$ ).

\section{Discussion}

In this study, $\beta$-sitosterol was isolated from P. curatellifolia extracts during extraction to determine active antimicrobial and biocidal compounds from this plant. Both fungi and bacteria remain major life threatening pathogens in humans, mostly to the immunocompromised or immunodeficient patients [33]. Despite the existence of potent antibiotic and antifungal agents, resistant and multiresistant strains are continuously emerging, imposing the need for a permanent search for alternative microbial agents [34]. Moreover, disinfection proved to be a frontline strategy of controlling microbial contamination and spread and development of resistance [35]. Therefore, this study was made to assess both the microbial and biocidal activity of phytochemicals from $P$. curatellifolia, as plants extracts are considered to be one of the best sources of alternative antimicrobials [36].
However, it is known that the activity of the plant extracts could be due to the different classes of phytochemicals present, their quantities, and the possible interactions with other constituents of the extract [1]. Furthermore, antimicrobial properties of plant extracts were observed to be influenced by several factors including the sample preparation and the extraction process $[16,36]$. Therefore, in the study, precautions were taken to ensure that potential active phytochemicals were not lost, distorted, or destroyed during the extraction. These include air-drying the sample at room temperature rather than oven drying at $60^{\circ} \mathrm{C}$ [16]. The effects of heat on potential active compounds were demonstrated by the significant reduction in the active anthocyanin content in some leaf extracts, possibly due to accelerated chalcone formation on exposure to high temperatures [37]. It was reported that bioactive phytochemicals, such as sinensetin and rosmarinic acid content, were affected by the oven and sunlight drying [38]. 


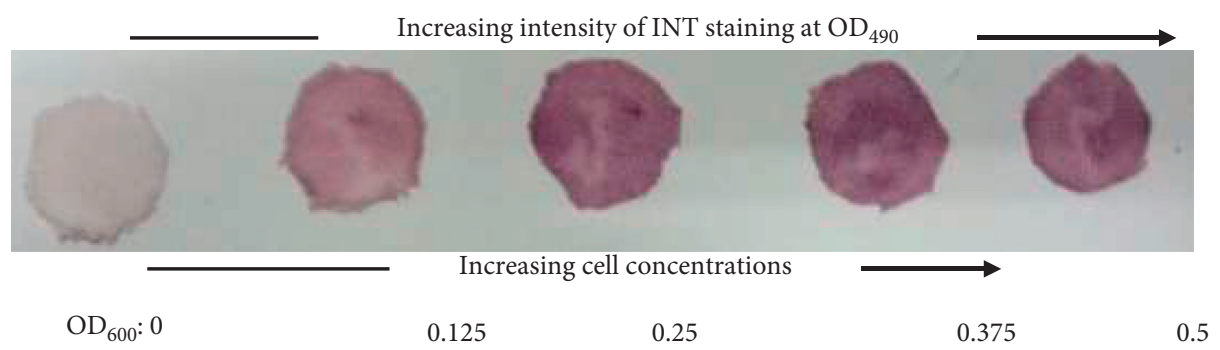

(a)

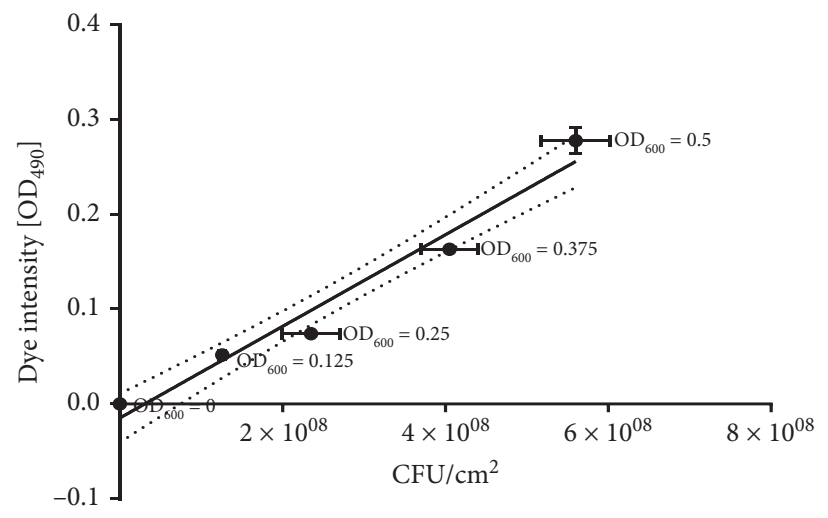

(b)

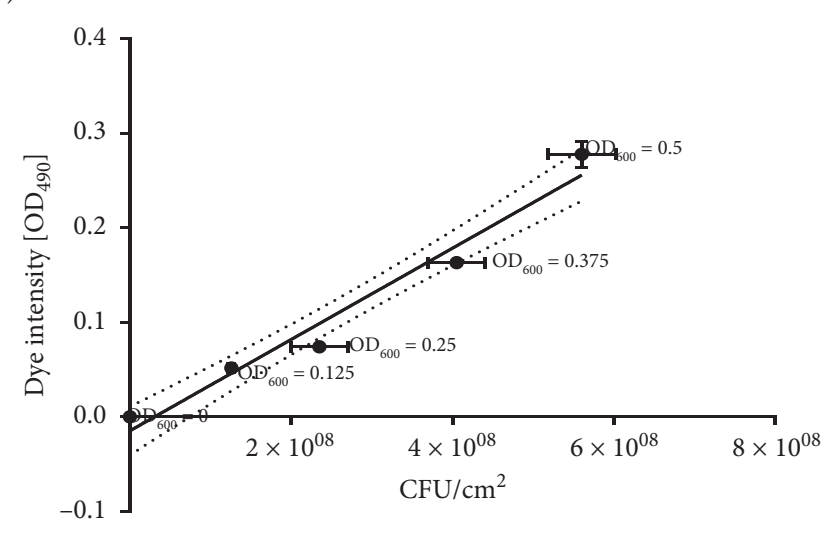

(c)

FIGURE 9: Standard curves of the INT staining intensity relative to the cell numbers. Solutions containing different numbers of $C$. $k r u s e i$ cells were applied onto Mendy fabric and stained with INT for 30 minutes (a). Bacteria/fungi CFU/ $\mathrm{cm}^{2}$ ( $x$-axis) are correlated to the intensity of INT staining at $\mathrm{OD}_{490}$ ( $y$-axis). Initial $\mathrm{OD}_{600}$ of the applied fungal/bacterial solution is indicated for each data point. By applying a volume of $100 \mu \mathrm{L}$, C. krusei with an initial $\mathrm{OD}_{600}$ of 0.5 was found to correspond to $5.6 \times 10^{8}$ fungal cells per $\mathrm{cm}^{2}$ of fabric after 1 hour incubation (b), while an $\mathrm{OD}_{600}$ of 0.5 equaled $3.15 \times 10^{10}$ M. smegmatis cells per $\mathrm{cm}^{2}$ (c). A linear regression (black line) through the background value precisely fits the staining intensity quantified for different cell numbers, indicating that there is no saturation of dye production in the tested cell densities. Error bars represent measurements for 4 individual fabric samples.

Maceration extraction technique based on the extracting power of different solvents was utilized in this study [16]. This technique targeted extraction of a wide range of compounds from the leaf material; hence, a combination of the total extraction (DCM-MeOH) and the serial exhaustive method was used on the same sample of $P$. curatellifolia. The DCM-MeOH extraction had the highest percentage yield, $5.53 \%$. This extraction technique uses a cosolvent extraction system of dichloromethane (nonpolar) and methanol (polar). The method was designed to extract both the polar and nonpolar compounds in a single extraction process, which justify the high yield compared to the polarity specific extraction methods [39].

In the polarity specific serial exhaustive methods used in this study, the methanol extraction had the highest yield, $3.31 \%$, followed by the water extract that had $3.0 \%$. The general observation was that the extraction yield increased as the polarity of the solvents increased. Increase in yield may be an indication of the presence of larger amounts of polar compounds in P. curatellifolia leaves compared to nonpolar compounds. Higher amounts of polar compounds are in accordance with previous observations that the dominant compounds in plants leaves are polar in nature [40].

Bhunu et al. [28] used a similar extraction method to extract phytochemicals from P. curatellifolia. Similar to the result shown in this study, their study [28] has also shown that the DCM-MeOH extraction had a higher yield compared to the serial exhaustive extraction. Reduction in yield of serial exhaustive extraction in this study may be probably due to the fact that the serial exhaustive extraction was done on the same plant materials that have some or most of the extracts already extracted by the DCM-MeOH extraction.

Furthermore, it was noted that the yield of DCM-MeOH extraction and the combined yield of the serial exhaustive extraction in the study by Bhunu et al. [28] were higher than the yields produced from the same extraction in the current study. Their study [28] has shown that the DCM-MeOH extraction yield was as high as $18 \%$ compared to $3.5 \%$ percent of this recent work. They also produced $12 \%$ of the combined serial exhaustive extraction compared to only $9 \%$ from the current study. Reduced yield in the current study is probably due to the material to solvent ratio of the extract. Bhunu et al. [28] used 1:10 $(w / v)$ ratio for extraction and produced better extraction yield compared to $1: 3(w / v)$ ratio used in this study.

These observations have justified the importance of careful selection of the extraction methods and solvent ratios for better phytochemicals extraction [41]. Since these two studies have used almost the same extraction methods and solvents produced different yields. The observation was that extraction efficiency in maceration of extraction is also affected by the solubility of the solid plant material and 


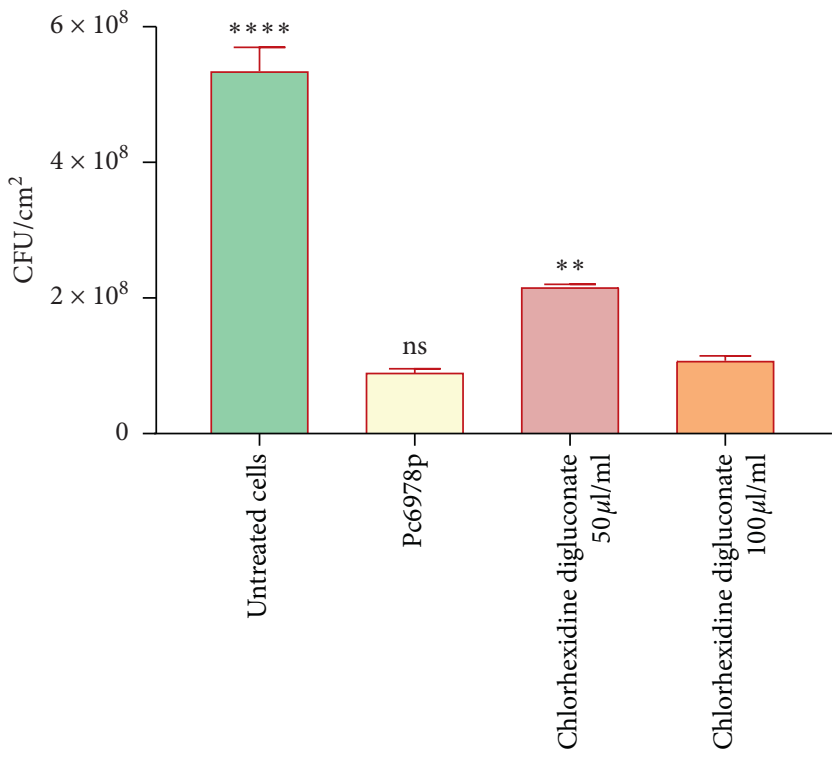

(a)

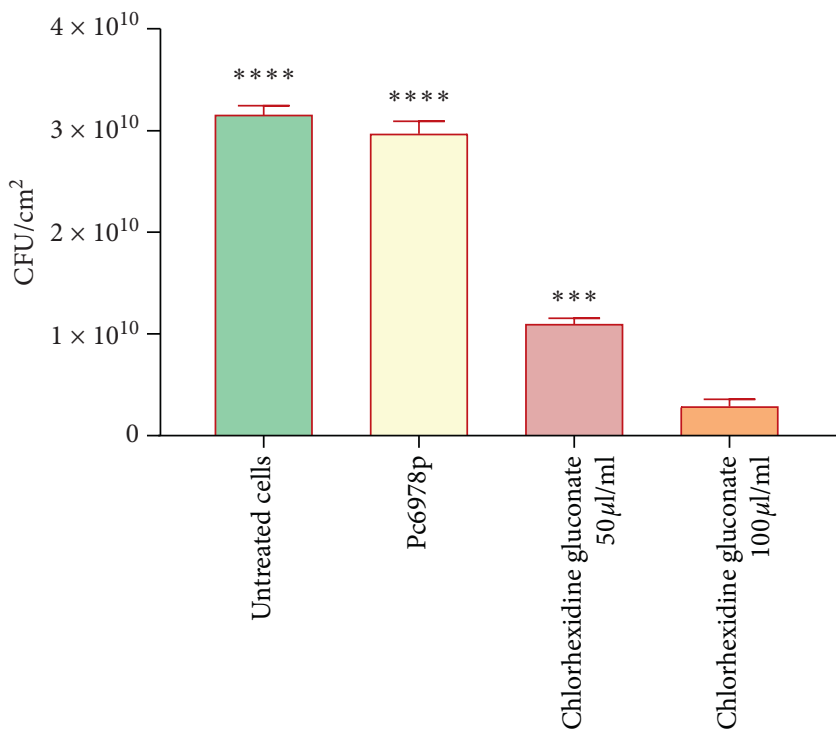

(b)

Figure 10: Biocidal effects of compound Pc6978p at a concentration of $100 \mu \mathrm{g} / \mathrm{mL}$ on C. krusei cells (a) and M. smegmatis cells (b) after incubation for 30 minutes at $37^{\circ} \mathrm{C}$. Untreated cells are the positive control of growth of cells; no biocide was added to the cell. Chlorhexidine digluconate $50 \mu \mathrm{g} / \mathrm{mL}$ and $100 \mu \mathrm{g} / \mathrm{mL}$ are the standard positive control of a biocide. Error bars represent the standard deviation of 2 individual replicates. The asterisk $(*)$ indicates the significant difference from the positive control chlorhexidine $100 \mu \mathrm{g} / \mathrm{mL}$ using statistical one-way ANOVA (where $* P<0.05, * * P<0.01, * * * P<0.001, * * * * P<0.0001$, and "ns" means no significant deference).

effective diffusion in the liquid extraction solvent [42]. The higher the solid to solvent ratio, the higher the yield [42]. Moreover, all stages of extractions, from the pre-extraction and extraction, are equally important in studying plant phytochemicals [41]. Sample preparation, such as grinding and drying, was also shown to affect the efficiency and phytochemical constituents of the final extractions, which eventually have an effect on the final extracts [16].

In vitro bioactivities of all the seven crude extracts were evaluated against the Gram-positive $S$. aureus, the Gramnegative K. pneumoniae, the acid-fast $M$. smegmatis, and the fungus C. krusei before fractionation and isolation of single compounds. The choice of purification of compound used in this study was activity-guided. According to Kuete et al. [43], antibacterial activity of a crude plant extract has been defined as significant when MIC is below $100 \mu \mathrm{g} / \mathrm{mL}$, moderate when $100 \mu \mathrm{g} / \mathrm{mL}<\mathrm{MIC}>625 \mu \mathrm{g} / \mathrm{mL}$, or low when MIC $>625 \mu \mathrm{g} / \mathrm{mL}$. The antimicrobial activity of a compounds is defined as significant when MIC is below $10 \mu \mathrm{g} /$ $\mathrm{mL}$, moderate when $10 \mu \mathrm{g} / \mathrm{mL}<\mathrm{MIC}>100 \mu \mathrm{g} / \mathrm{mL}$, or low when MIC $>100 \mu \mathrm{g} / \mathrm{mL}$ [43]. Therefore, the bioactivity assay in this study was guided by those standards. Extracts were considered to be significantly active when MIC values below $100 \mu \mathrm{g} / \mathrm{mL}$ were obtained on at least one tested organism. Interestingly, 5 out of 7 extracts were active against at least one test microbe.

M. smegmatis was the most susceptible to most of the P. curatellifolia leaf extracts, with the ethanol and methanol extract being the most active extracts against $M$. smegmatis cell growth, with an MIC of $25 \mu \mathrm{g} / \mathrm{mL}$. The DCM-MeOH extract and the acetone extract had an MIC of $50 \mu \mathrm{g} / \mathrm{mL}$ on
M. smegmatis. The activities of extracts against M. smegmatis were observed to generally increase as extraction solvent polarity increased from hexane to methanol. Out of the four extracts that inhibited the growth of M. smegmatis cells, only the $\mathrm{DCM}-\mathrm{MeOH}$ and the methanol extract had MBC values of less than or equal to $100 \mu \mathrm{g} / \mathrm{mL}$ against $M$. smegmatis. This observation indicates possible bactericidal effects of both the $\mathrm{DCM}-\mathrm{MeOH}$ and the methanol extract again M. smegmatis at concentration of $100 \mu \mathrm{g} / \mathrm{mL}$, since the two extracts completely inhibited the visible M. smegmatis growth on the agar plates after incubation at $37^{\circ} \mathrm{C}$ for 24 . The acetone and ethanol extracts were bacteriostatic against $M$. smegmatis at a concentration less than or equal to $100 \mu \mathrm{g} / \mathrm{mL}$. Significant bactericidal effects of DCM-MeOH extracts against $M$. smegmatis may be because of synergism of different compounds since the DCM-MeOH extracts contained a wide range of compounds including both polar and nonpolar compounds.

Bhunu et al. [28] also demonstrated susceptibility of M. smegmatis cells to P. curatellifolia leaf extracts. According to their study [28], the MIC of the P. curatellifolia leaf extracts was $6.2 \mu \mathrm{g} / \mathrm{mL}$ for the acetone extract, $12.5 \mu \mathrm{g} / \mathrm{mL}$ for both the ethanol and the $\mathrm{DCM}-\mathrm{MeOH}$ extracts, and $50 \mu \mathrm{g} / \mathrm{mL}$ for both the methanol and ethyl acetate extracts. The MIC values from the study by Bhunu et al. [28] were slightly lower than the value obtained in this study. This may be due to factors including the effectiveness of the extraction and preparative methods [16]. Susceptibility of M. smegmatis to $P$. curatellifolia leaf extracts may be due to the destruction of waxy cell envelop on mycobacteria [42]. The waxy cell envelop is known to be innate, making the mycobacteria the least susceptible to antimicrobial agents [42]. However, 
some phenolics, e.g., the gallic acid, were demonstrated to interact with these membranes envelops [42].

The hexane extract was among the extracts that showed significant antimicrobial activity according to [43] standards. Despite being less potent to all the bacterial test organisms, the hexane extract showed significant antifungal activity against C. krusei. This may be an indication that nonpolar extracts of $P$. curatellifolia have less antibacterial activities but stronger antifungal. The MIC of the hexane extract on C. krusei was $25 \mu \mathrm{g} / \mathrm{mL}$. The extract was not fungicidal at a concentration less than or equal to $100 \mu \mathrm{g} / \mathrm{mL}$. Interestingly, of all the extracts, only the hexane extract showed potent antifungal activity. Silva Sa et al. [44] have shown that nonpolar fractions including the hexane and dichloromethane fraction from Myrcia tomentosa (Aubl.) DCM leaf extracts showed antifungal activity against Candida species with low MIC values, which ranged from 4 to $256 \mu \mathrm{g} / \mathrm{mL}$. Therefore, it is most likely that the constituents of the nonpolar extracts are responsible for the anti-Candida activity of $P$. curatellifolia. The probable reason for the strong activity of hexane extract against the $C$. krusei may be the interaction between C. krusei cells and nonpolar compounds, since the strong hydrophobicity in the C. krusei cell membrane allows stronger affinity to nonpolar compounds [45]. In a similar study, Samie et al. [46] reported that hexane extracts were among the active extracts against C. krusei. Samie et al. [46] went on to conclude that most Candida species were susceptible to plant hexane extracts suggesting that many of the antifungal components of these plants were nonpolar compounds [45]. Lack of significant antibacterial activity by the hexane extract with some solvents showing activity is in accordance with the observations by Peni et al. [22], who showed that different solvent extracts of the same plant may have different pharmacological properties.

None of the extracts used in this study were able to completely inhibit both the Gram-positive S. aureus and Gram-negative K. pneumoniae at concentration less than or equal to $100 \mu \mathrm{g} / \mathrm{mL}$. Lack of activity below $100 \mu \mathrm{g} / \mathrm{mL}$ of extracts against $S$. aureus was previously shown by Oshomoh and Idu [47], who indicated that the least MIC of some P. curatellifolia extracts was $3.125 \mathrm{mg} / \mathrm{mL}$ against $S$. aureus. However, the results from this study have shown that the DCM-MeOH extract had considerable activity against Gram-positive cells at a concentration of $100 \mu \mathrm{g} / \mathrm{mL}$. At that concentration, the DCM-MeOH extract inhibited up to $90 \%$ of the growth of $S$. aureus cells. The activities of most extracts against $S$. aureus were generally above $50 \%$. However, the higher activity against $S$. aureus in this study was generally observed with polar $P$. curatellifolia extracts. These observations were in agreement with those by Peni et al. [22].

The DCM-MeOH had the highest activity against the Gram-negative $K$. pneumoniae inhibiting up to $74.8 \%$ of cell growth. A previous study by Halilu et al. [48] showed that the MIC of $P$. curatellifolia extracts against some Gram-negative microbes was above $100 \mu \mathrm{g} / \mathrm{mL}$ limit. The least MIC of $P$. curatellifolia extracts against $P$. aeruginosa was $1.5 \mathrm{mg} / \mathrm{mL}$ [48]. According to Halilu et al. [48] P. curatellifolia extracts were more active against Gram-positive compared to the Gram-negative microbes. The results from the study by Halilu et al. [48] agree with those from this study, showing that the
DCM-MeOH leaf extracts from $P$. curatellifolia had a higher activity against $S$. aureus (89.9\%) compared to K. pneumoniae (74.5\%). The susceptibility of the Gram-positive bacteria may be due to the disruption of the cell walls by some phytochemicals present in the crude extracts commonly classified as phytoanticipins [49].

After evaluating the activity of the crude extracts, extracts that showed considerable activity against at least one of the test microbes were selected for fractionation and isolation of pure compounds. The hexane, methanol, ethanol, and DCM-MeOH were selected for fractionation. A chromatogram with more than a single spot on the TLC was considered not pure. The purple compound Pc6978p (Rf 0.38) was considered pure since only a single spot was observed on the TLC plate. After elution of the chromatograms from the preparative TLC silica, compound Pc6978p was concentrated to a white crystalline powder. Pc4963r, Pc4962w, and Pc6978o were concentrated to green crystalline powder, white crystalline powder, and green crystalline powder, respectively. The structure of Pc6978p was determined to be $\beta$-sitosterol on the basis of ${ }^{1} \mathrm{H}$ and ${ }^{13} \mathrm{C}$ NMR spectroscopic data and by comparing them to those reported in the literature [50].

$\beta$-Sitosterol is one of most spread phytosterols in the plant kingdom [23]; $\beta$-sitosterol was isolated previously from a number of plant species [51-53], but to the best of our knowledge, $\beta$-sitosterol was isolated for the first time from $P$. curatellifolia extracts. In vitro bioactivities of $\beta$-sitosterol were evaluated against the four test organisms. The isolated $\beta$-sitosterol failed to show significant activity against all the test organisms according to Kuete [43] proposed standards. Nonetheless, the compound managed to reduce the growth of M. smegmatis cells by $97.9 \%$. There is a notable loss of activities of Pc6978p compared to the activity of some crude extracts (DCM:methanol, acetone, ethanol, and methanol) against $M$. smegmatis. This may be attributed to loss of synergism of compounds in the crude extracts through purification. Synergistic effects occur when two compounds increase one another's potency, resulting in mixtures that have stronger effect than predicted based on activities of their components in isolation [54]. High antimicrobial activity of some crude extracts observed may be due to the synergistic effects of the compounds present in the extracts [54]. For example, combinations of thymol and eugenol were shown to have synergistic effects against E. coli [55].

$\beta$-Sitosterol reduced the cell growth of the Gram-positive S.aureus and Gram-negative K. pneumoniae by $75 \%$ and $39 \%$, respectively, at $100 \mu \mathrm{g} / \mathrm{mL}$. It was also noted that the isolated $\beta$-sitosterol has significantly reduced activity against these two microbe as compared to the activity of the DCM: methanol and methanol extracts. This may be an indication that the most active compounds against Gram-positive and Gram-negative bacteria may be more in polar extracts (e.g., methanol extracts) than in nonpolar ones, since some studies have reported the isolation of $\beta$-sitosterol in nonpolar solvents [23]. Loss of activity of the isolated $\beta$-sitosterol may also be due to loss of synergistic effects of compounds present in extracts against $S$. aureus and K. pneumoniae. 
While the activity of $\beta$-sitosterol cannot be classified as significant [43], results from this study showed significant activity of this compound against all the test bacterial strains. The observed antibacterial activity of the isolated compound are in agreement with the reported antibacterial activity of $\beta$-sitosterol against the same bacterial strains [52]. Using the disc-diffusion method [52], other researchers have also reported low activity of $\beta$-sitosterol against both the Gramnegative and Gram-positive cells. The growth inhibition in that study was $11 \mathrm{~mm}$ and $13.5 \mathrm{~mm}$ against $S$. aureus and Gram-negative E. coli, respectively, using the disc-diffusion method [52]. There are also reports that show antibacterial activity of $\beta$-sitosterol against several bacterial species $[23,56]$. Therefore, from this study, it was observed that $\beta$-sitosterol has activity against the test bacterial cells, although the activity can only be classified as low according to Kuete [43]. Low but statistically significant activity of the $\beta$-sitosterol against Gram-positive, Gram-negative, and acid-fast bacteria has highlighted a degree of the broadspectrum activity of the $\beta$-sitosterol. However, of all the activities of $\beta$-sitosterol, the lowest observed was against Gram-negative bacteria.

$\beta$-Sitosterol had moderate activity against $C$. krusei with an MIC value of $25 \mu \mathrm{g} / \mathrm{ml}$ and MFC of $50 \mu \mathrm{g} / \mathrm{mL}$ against $C$. krusei. The results confirm reports suggesting that phytosterols do have an antifungal potential [57]. From this study, an increase in in activity against $C$. krusei was observed between the activity of the most active hexane extract and activity of the purified compound. The hexane extract failed to completely inhibit the growth of C. krusei after incubation at a concentration of $100 \mu \mathrm{g} / \mathrm{mL}$ for $18 \mathrm{hrs}$, while the pure compound was able to kill all the cells at $50 \mu \mathrm{g} / \mathrm{mL}$ in the same incubation conditions.

The enhancement of antimicrobial activity of $\beta$-sitosterol as a single entity chemical may be due to the elimination of the antagonistic effects of different compounds found in crude extracts. Antagonistic effects occur when two compounds inhibit one another's activities, such that mixtures are less effective than predicted based on the activities of each compound in isolation [55]. Antagonistic effects of different compounds in extracts are known to reduce the activity of some active compounds [54]. For example, eugenol and thymol had antagonistic effects against Crithidia fasciculata [58]. Hence, purification of some compounds is sometimes recommended to achieve the highest antimicrobial activity of some phytochemicals [58].

The antifungal activity of $\beta$-sitosterol observed in this study is in agreement with a previous study reporting that $\beta$-sitosterol inhibited the growth of C. albicans and C. krusei at $50 \mu \mathrm{g} / \mathrm{mL}$ [59]. Although some studies have indicated that $\beta$-sitosterol was fungistatic rather than fungicidal [24], this study has shown that $\beta$-sitosterol was fungicidal at $50 \mu \mathrm{g} / \mathrm{mL}$. However, from these observations, further analysis of $\beta$-sitosterol on the anti-Candida species, especially C. krusei, may be necessary since this fungal species is clinically significant. C. krusei induces candidiasis which is also caused by many other species of the Candida genus [60]. C. krusei is also listed as emerging fungal nosocomial pathogen whose infection is common among immunocompromised patients and those with hematological malignancies [60].
Therefore, further analysis may be useful to determine if the $\beta$-sitosterol can be used to treat such fungal related ailment, as well as to unlock more of its value in human health and hygiene. For example, its synergistic potential can be used to enhance the activity of already present antimicrobial agents to minimize microbial resistance. The isolated $\beta$-sitosterol can also be used as an additive to present antifungal agents. Additive effects indicate that the effects of chemicals are independent of one another [55] but have similar modes of action, such that adding a second compound has the same effect as adding more of the first compound [61]. A clinical example of additive effects due to independent actions of phytochemicals, artemisinin, and curcumin against malaria was descried by Nandakumar et al. [62].

Chemical composition and structures of the contents in Pc4963r, Pc4962w, and Pc6978o could not be determined in this study. However, antimicrobial activities of $\mathrm{Pc} 4963 \mathrm{r}$ and Pc4962w were evaluated against all the test organisms. Antimicrobial activities of Pc6978o were not evaluated due to very low yield. The highest activities of both Pc4963r and Pc4962w were observed against C. krusei cells; both compounds showed moderate activity against C. krusei. Pc4962w had MIC and MFC values of $25 \mu \mathrm{g} / \mathrm{mL}$ and $100 \mu \mathrm{g} / \mathrm{mL}$, respectively. Pc4963r had MIC and MFC values of $50 \mu \mathrm{g} / \mathrm{mL}$ and $100 \mu \mathrm{g} / \mathrm{mL}$ against C. krusei. The study has shown an increase in activity against C. krusei between the activity of the most active hexane extract and the activity of both Pc4963r and Pc4962w. The hexane extract failed to totally eliminate the C. krusei cells following incubation at a concentration of $100 \mu \mathrm{g} / \mathrm{mL}$ for 18 hours. On the other hand, Pc4963r and Pc4962w were fungicidal cells at $100 \mu \mathrm{g} / \mathrm{mL}$ under the same incubation conditions. Improvement in activity of both compounds may be due the elimination of the antagonistic effects of different compounds found in crude extracts. The similarity of these results to those of $\beta$-sitosterol coupled with the fact that $\beta$-sitosterol, Pc4963r, and Pc4962w were isolated from closely related pools may lead to the suggestion that both Pc4963r and Pc4962w may also be phytosterols. This suggestion has been derived from a previous suggestion that most phytosterols have an antifungal potential [49].

After determination of the biological activity of the isolated compound, the study went on to determine the applicability of the obtained results. Therefore, following the activity-guided approach of analysis, biocidal effects of Pc6978p were evaluated against C. krusei cells and M. smegmatis on the Mendy fabric. The Mendy fabric is the most used material to make uniforms for nurses in most Zimbabwean hospitals. However, it was noted that, in most hospital setups, nurses are the most vulnerable to microbial contamination since they are the primary handlers of infected and sick people [63]. In addition, nurses spend most of the time in sick people's wards, which may increase the chances of cloth contamination by infection pathogens [63].

Microbial contamination of health workers' cloths, surfaces, and equipment plays a significant role in the spread of pathogens [15]. Successful transmission of pathogens depends on many factors, including the capacity of microorganisms to remain viable on dry surfaces, their resistance to disinfectants, 
and the frequency at which infected surfaces or equipment comes in contact with patients and healthcare staff [15]. Furthermore, antimicrobial resistance could be acquired through exposure of microbes to deferent conditions and substances while being attached to textiles and surfaces $[64,65]$. Therefore, evaluation of possible alternative sources of biocidal compounds was investigated in this study.

Compound Pc6978p had 86\% biocidal activity on C. krusei cells attached to the Mendy fabric. That is, at a concentration of $100 \mu \mathrm{g} / \mathrm{mL}, \beta$-sitosterol removed and was fungicidal to about $5.04 \times 10^{8} \mathrm{C}$. krusei cells per $\mathrm{cm}^{2}$ of Mendy fabric after 30 minutes of incubation. These observations show that Pc6978p had better biocidal activity compared to the known biocide chlorhexidine digluconate which had $80 \%$ activity against the same cells under the same condition. However, there was no statistically significant difference between the biocidal activity of Pc6978p and chlorhexidine digluconate. From this study, it can be proposed that the compound can be a candidate for the formulation of alternative biocides used to decontaminate textiles. A study by Diba [66] has shown that hospital textiles, mostly blankets, are the main sources of C. krusei contamination. Several studies indicate that different Candida species can have similar adherence properties to cotton and other fabrics [66], as well as to plastics and other synthetic materials [66]. Furthermore, it is suggested that significant environmental contamination in hospital setup is from Candida species [66], especially antifungal C. krusei [67]. It is possible that the strong hydrophobicity in the C. krusei cell membrane allows stronger attachment to nonpolar surfaces and these include catheter surfaces, compromising sterility and differential diagnosis [35]. Therefore, $\beta$-sitosterol can also be formulated into some of the disinfectants that are used in hospital settings to reduce $C$. krusei contamination. Hence, further studies on the biocidal effects of Pc6978p against C. krusei on other surfaces are recommended.

Even though compound Pc6978p showed high growth reduction effects on $M$. smegmatis in in vitro antimicrobial assays, it failed to exhibit biocidal activity against the M. smegmatis attached to the Mendy textile. Pc6978p only reduced $6 \%$ of the viable cells compared to the positive control chlorhexidine digluconate that had $90 \%$ biocidal activity under the same conditions. The observations may suggest that Pc6978p is less effective as a biocide against $M$. smegmatis. However, it is important to note that the effectiveness of biocides is influenced by many factors, such as concentration, contact time, and environmental conditions to which it is applied [68, 69]. The condition, whether in suspension, adhering to a surface, or in a biofilm, would have an effect on the effectiveness of biocides [70]. Therefore, all these effects should be investigated in future, so that full biocidal potential of $\beta$-sitosterol and other natural compounds from this plant can be exploited.

\section{Conclusion}

P. curatellifolia leaf extracts, extracted in this study, have been shown to contain phytochemicals that inhibit the growth of test bacterial and fungal species. This is in agreement with the use of this plant in traditional medicine.
The DCM-methanol and ethanol extracts were the most active against most test bacterial species. Mycobacterium smegmatis was the most susceptible to most extracts. $\beta$-sitosterol showed fungicidal activity against C. krusei and potent biocidal activity against $C$. krusei cells attached to the Mendy textile. However, further work has to be done to determine if the isolated compounds can be used to treat fungal and bacterial related ailment in model system, as well as to unlock their potential use in human health industry as biocides.

\section{Data Availability}

The datasets used and/or analyzed during the current study are available from the corresponding author on reasonable request.

\section{Conflicts of Interest}

The authors declare that they have no conflicts of interest.

\section{Acknowledgments}

Support from the Swedish International Development Agency (SIDA) through the International Science Programme (ISP) (ISP IPICS: ZIM01, Uppsala University, Uppsala, Sweden) and the International Foundation in Sciences (IFS F/3413-03F, Stockholm, Sweden) is acknowledged. F/3413-03F supported the research under the title "Screening Natural Plant Products from Selected Plants from Zimbabwe as a Source of Anti-infective Compounds for Phytomedicines Development." ISP IPICS: ZIM01 supported the research under the title "Biomolecular Interactions Analyses." Support from the Alliance for Global Health and Science (University of California, Berkeley) is acknowledged. The authors acknowledge the assistance of Mr. Christopher Chapano, a taxonomist with the National Herbarium and Botanical Gardens, Harare, Zimbabwe, in the authentication of the plant sample names.

\section{References}

[1] R. E. Etame, R. S. Mouokeu, C. L. C. Pouaha et al., "Effect of fractioning on antibacterial activity of enantia chlorantha oliver (annonaceae) methanol extract and mode of action," Evidence-Based Complementary and Alternative Medicine, vol. 2018, Article ID 4831593, 13 pages, 2018.

[2] I. J. Umaru, F. A. Badruddin, and H. A. Umaru, "Phytochemical screening of essential oils and antibacterial activity and antioxidant properties of Barringtonia asiatica (L) leaf extract," Biochemistry Research International, vol. 2019, Article ID 7143989, 6 pages, 2019.

[3] B. Chang and G. Frendl, "Nosocomial infections," in Essential Clinical Anesthesia Review: Keywords, Questions and Answers for the BoardsCambridge University Press, Cambridge, UK, 2015.

[4] T. Hautala, I. Ikäheimo, H. Husu et al., "A cluster of Candida kruseiinfections in a haematological unit," BMC Infectious Diseases, vol. 7, no. 1, 2007. 
[5] A. Coates, Y. Hu, R. Bax, and C. Page, "The future challenges facing the development of new antimicrobial drugs," Nature Reviews Drug Discovery, vol. 1, no. 11, pp. 895-910, 2002.

[6] S. Manandhar, S. Luitel, and R. K. Dahal, "In vitro antimicrobial activity of some medicinal plants against human pathogenic bacteria," Journal of Tropical Medicine, vol. 2019, Article ID 1895340, 5 pages, 2019.

[7] A. C. Singer, H. Shaw, V. Rhodes, and A. Hart, "Review of antimicrobial resistance in the environment and its relevance to environmental regulators," Frontiers in Microbiology, vol. 7, pp. 1-22, 2016.

[8] M. R. Williams, R. D. Stedtfeld, X. Guo, and S. A. Hashsham, "Antimicrobial resistance in the environment," Water Environment Research, vol. 88, no. 10, pp. 1951-1967, 2016.

[9] J. Szostak-Kotowa, "Biodeterioration of textiles," International Biodeterioration \& Biodegradation, vol. 53, no. 3, pp. 165-170, 2004.

[10] P. Stiefel, J. Schneider, C. Amberg, K. Maniura-Weber, and Q. Ren, "A simple and rapid method for optical visualization and quantification of bacteria on textiles," Scientific Reports, vol. 6, no. 1, pp. 1-9, 2016.

[11] S. Schmidt-Emrich, P. Stiefel, P. Rupper et al., "Rapid assay to assess bacterial adhesion on textiles," Materials, vol. 9, no. 4, pp. 249-313, 2016.

[12] J. A. Otter, K. Vickery, J. T. Walker et al., "Surface-attached cells, biofilms and biocide susceptibility: implications for hospital cleaning and disinfection," Journal of Hospital Infection, vol. 89, no. 1, p. 16, 2015.

[13] J. M. Boyce, "Environmental contamination makes an important contribution to hospital infection," Journal of Hospital Infection, vol. 65, pp. 50-54, 2007.

[14] B. P. Marasini, P. Baral, P. Aryal et al., "Evaluation of antibacterial activity of some traditionally used medicinal plants against human pathogenic bacteria," BioMed Research International, vol. 2015, Article ID 265425, 6 pages, 2015.

[15] I. B. Gomes, J. Malheiro, F. Mergulhão, J.-Y. Maillard, and M. Simões, "Comparison of the efficacy of natural-based and synthetic biocides to disinfect silicone and stainless steel surfaces," Pathogens and Disease, vol. 74, no. 4, Article ID $\mathrm{ftw014,} 2016$.

[16] A. Nn, "A review on the extraction methods use in medicinal plants, principle, strength and limitation," Medicinal \& Aromatic Plants, vol. 4, no. 3, pp. 3-8, 2015.

[17] H. Mohamed Sham Shihabudeen, D. Hansi Priscilla, and K. Thirumurugan, "Antimicrobial activity and phytochemical analysis of selected Indian folk medicinal plants," International Journal of Pharma Sciences and Research, vol. 1, no. 10, 2010.

[18] G. I. Ameh and C. S. Eze, "Phytochemical constituents of some Nigerian plants," Bio-Research, vol. 8, no. 1, pp. 685-688, 2010.

[19] U. Pandya, A. Doshi, and N. S. Sahay, "Development of herbal disinfectants formulation for mopping households and its antibacterial activity," Natural Product Research, vol. 31, no. 22, p. 2665, 2017.

[20] A. Maroyi, "Traditional use of medicinal plants in southcentral Zimbabwe: review and perspectives," Journal of Ethnobiology and Ethnomedicine, vol. 9, no. 1, p. 31, 2013.

[21] C. Kraft, K. Jenett-Siems, K. Siems et al., "In vitro antiplasmodial evaluation of medicinal plants from Zimbabwe," Phytotherapy Research, vol. 17, no. 2, pp. 123-128, 2003.

[22] I. J. Peni, C. M. Elinge, H. Yusuf et al., "Phytochemical screening and antibacterial activity of Parinari curatellifolia stem extract," Journal of Medicinal Plant Research, vol. 4, no. 20, pp. 2099-2102, 2010.

[23] M. M. Ododo, M. K. Choudhury, and A. H. Dekebo, "Structure elucidation of $\beta$-sitosterol with antibacterial activity from the root bark of Malva parviflora," Springerplus, vol. 5, no. 1, 2016.

[24] A. Sen, P. Dhavan, K. K. Shukla, S. Singh, and G. Tejovathi, "Analysis of IR, NMR and antimicrobial activity of $\beta$-sitosterol isolated from momordica charantia," Science Secure Journal of Biotechnology, vol. 1, no. 1, pp. 9-13, 2012.

[25] S. Saeidnia, "The story of beta-sitosterol-a review," European Journal of Medicinal Plants, vol. 4, no. 5, pp. 590-609, 2014.

[26] K. Inweregbu, J. Dave, and A. Pittard, "Nosocomial infections," Continuing Education in Anaesthesia Critical Care \& Pain, vol. 5, no. 1, pp. 14-17, 2005.

[27] V. Krcmery, S. Spanik, A. Kunova et al., "Nosocomial Candida krusei Fungemia in cancer patients: report of 10 cases and review," Journal of Chemotherapy, vol. 11, no. 2, pp. 131-136, 1999.

[28] B. Bhunu, R. Mautsa, and S. Mukanganyama, "Inhibition of biofilm formation in Mycobacterium smegmatis by Parinari curatellifolia leaf extracts," BMC Complementary and Alternative Medicine, vol. 17, no. 1, pp. 1-10, 2017.

[29] R. F. Cockerill, A. J. Hindler, A. P. Bradford et al., "M07-A10: methods for dilution antimicrobial susceptibility tests for bacteria that grow aerobically; approved standard-tenth edition," CLSI (Clinical and Laboratory Standards Institute), vol. 35, no. 2, 2015.

[30] J. Eloff, "A sensitive and quick microplate method to determine the minimal inhibitory concentration of plant extracts for bacteria," Planta Medica, vol. 64, no. 8, pp. 711-713, 1998.

[31] M. Balouiri, M. Sadiki, and S. K. Ibnsouda, "Methods for in vitro evaluating antimicrobial activity: a review," Journal of Pharmaceutical Analysis, vol. 6, no. 2, pp. 71-79, 2016.

[32] M. Arora and A. N. Kalia, "Isolation and characterization OF stigmasterol and $\beta$-sitosterol-D-glycoside from ethanolic extract of the stems of salvadora persica linn," International Journal of Pharmacy and Pharmaceutical Sciences, vol. 5, pp. 1-5, 2013.

[33] E. O. Iwalewa, M. M. Suleiman, L. K. Mdee, and J. N. Eloff, "Antifungal and antibacterial activities of different extracts of Harungana madagascariensis stem bark," Pharmaceutical Biology, vol. 47, no. 9, pp. 878-885, 2009.

[34] L. L. Silver and K. A. Bostian, "Discovery and development of new antibiotics: the problem of antibiotic resistance," Antimicrobial Agents and Chemotherapy, vol. 37, no. 3, pp. 377383, 1993.

[35] J. F.. Malheiro, J. Y. Maillard, F. Borges, and C. Simões, "Biocide potentiation using cinnamic phytochemicals and derivatives," Molecules, vol. 24, no. 21, pp. 13-15, 2019.

[36] S. Savadi, M. Vazifedoost, Z. Didar, M. M. Nematshahi, and E. Jahed, "Phytochemical analysis and antimicrobial/antioxidant activity of cynodon dactylon (L.) pers. Rhizome methanolic extract," Journal of Food Quality, vol. 2020, Article ID 5946541, 10 pages, 2020.

[37] L. A. Pacheco-Palencia, C. E. Duncan, and S. T. Talcott, "Phytochemical composition and thermal stability of two commercial Açai species, Euterpe oleracea and Euterpe precatoria," Food Chemistry, vol. 115, no. 4, pp. 1199-1205, 2009.

[38] S. Abdullah, A. R. Shaari, and A. Azimi, "Effect of drying methods on metabolites composition of misai kucing (orthosiphon stamineus) leaves," APCBEE Procedia, vol. 2, pp. 178-182, 2012. 
[39] N. Hashim, A. R. Shaari, A. Soh Mamat, and S. Ahmad, "Effect of differences methanol concentration and extraction time on the antioxidant capacity, phenolics content and bioactive constituents of Orthosiphon stamineus extracts," MATEC Web of Conferences, vol. 78, pp. 1004-1007, 2016.

[40] U. Chukwudi, F. Ayodeji, J. Amos, and O. Olawunmi, "Antibacterial activity and phytochemical evaluation of the leaf root and stem bark extracts of parinari curatellifolia (planch. ex benth)," International Journal of Advanced Chemistry, vol. 2, no. 2, p. 178, 2014.

[41] K. P. Ingle, A. G. Deshmukh, D. A. Padole et al., "Phytochemicals: extraction methods, identification and detection of bioactive compounds from plant extracts," Journal of Pharmacognosy and Phytochemistry, vol. 6, no. 1, pp. 32-36, 2017.

[42] C. Y. Cheok, H. A. K. Salman, and R. Sulaiman, "Extraction and quantification of saponins: a review," Food Research International, vol. 59, pp. 16-40, 2014.

[43] V. Kuete, "Potential of Cameroonian plants and derived products against microbial infections: a review," Planta Medica, vol. 76, no. 14, pp. 1479-1491, 2010.

[44] F. D. Silva Sa, J. de Paula, P. dos Santos et al., "Phytochemical analysis and antimicrobial activity of Myrcia tomentosa (Aubl.) DC. leaves," Molecules, vol. 22, no. 7, pp. 1100-1110, 2017.

[45] Y. H. Samaranayake, P. C. Wu, L. P. Samaranayake, M. So, and K. Y. Yuen, "Adhesion and colonisation of Candida krusei on host surfaces," Journal of Medical Microbiology, vol. 41, no. 4, pp. 250-258, 1994.

[46] A. Samie, T. Tambani, E. Harshfield, E. Green, J. N. Ramalivhana, and P. O. Bessong, "Antifungal activities of selected Venda medicinal plants against candida albicans, Candida krusei and cryptococcus neoformans isolated from South African AIDS patients," African Journal of Biotechnology, vol. 9, no. 20, pp. 2965-2976, 2010.

[47] E. O. Oshomoh and M. Idu, "Antimicrobila activity of ethanol and aqueous extracts of Parinari curatellifolia (stem) on dental caries causing microbes," International Journal of Pharmaceutical Sciences and Research, vol. 3, no. 7, pp. 2113-2118, 2012.

[48] M. E. Halilu, G. G. Yebpella, and L. G. Hassan, "Preliminary phytochemical screening, antibacterial activity and elemental analysis of the leaves and the root bark of Parinari curatellifolia planch ex benth (chrysobalanaceae)," Continental Journal of Pharmaceutical Sciences, vol. 4, no. 903, pp. 1-5, 2010.

[49] M. Simões, R. N. Bennett, and E. A. S. Rosa, "Understanding antimicrobial activities of phytochemicals against multidrug resistant bacteria and biofilms," Natural Product Reports, vol. 26, no. 6, pp. 746-757, 2009.

[50] V. A. Nyigo, X. Peter, M. Faith, M. M. Hamisi, H. M. Robinson, and G. Fouche, "Isolation and identification of euphol and $\beta$-sitosterol from the dichloromethane extracts of Synadenium glaucescens," Journal of Phytopharmacology, vol. 5, no. 3, pp. 100-104, 2016.

[51] D. N. Tsafack, M. A. Yameen, G. S. S. Njateng et al., "GC/MS analysis, antisalmonellal potential of methanol leaf extracts of Tristemma mauritianum and effects on hematological parameters on Wistar rats infected with Salmonella typhi," International Journal of Pharmaceutics, vol. 7, no. 2, pp. 120-131, 2017.

[52] A. Edilu, L. Adane, and D. Woyessa, "In vitro antibacterial activities of compounds isolated from roots of Caylusea abyssinica," Annals of Clinical Microbiology and Antimicrobials, vol. 14, no. 1, pp. 1-8, 2015.
[53] P. Luhata Lokadi and M. Munkombwe Namboole, "Isolation and characterisation of stigmasterol and B -sitosterol from odontonema strictum (Acanthaceae)," Journal of Innovations in Pharmaceutical and Biological Sciences, vol. 2, pp. 88-96, 2015.

[54] E. C. Palmer-Young, B. M. Sadd, R. E. Irwin, and L. S. Adler, "Synergistic effects of floral phytochemicals against a bumble bee parasite," Ecology and Evolution, vol. 7, no. 6, pp. 1836-1849, 2017.

[55] R.-s. Pei, F. Zhou, B.-p. Ji, and J. Xu, "Evaluation of combined antibacterial effects of eugenol, cinnamaldehyde, thymol, and carvacrol against E. coli with an improved method," Journal of Food Science, vol. 74, no. 7, pp. M379-M383, 2009.

[56] S. C. Hess, R. L. Brum, N. K. Honda et al., "Antibacterial activity and phytochemical analysis of Vochysia divergens (Vochysiaceae)," Journal of Ethnopharmacology, vol. 47, no. 2, pp. 97-100, 1995.

[57] M. Mbambo, B. Odhav, and V. Mohanlall, "Antifungal activity of stigmasterol, sitosterol and ergosterol from Bulbine natalensis baker (Asphodelaceae)," Journal of Medicinal Plants Research, vol. 6, no. 38, pp. 5135-5141, 2012.

[58] C. M. O. Azeredo and M. J. Soares, "Combination of the essential oil constituents citral, eugenol and thymol enhance their inhibitory effect on Crithidia fasciculata and Trypanosoma cruzi growth," Brazilian Journal of Pharmacognosy, vol. 23, no. 5, pp. 762-768, 2013.

[59] I. Yinusa, N. I. George, R. G. Ayo, and Y. Rufai, "Evaluation of the pharmacological activities of beta-sitosterol isolated from the bark of sarcocephalus latifolius (smith bruce)," Global Journal of Pure and Applied Chemistry Research, vol. 3, no. 3, pp. 7-14, 2015.

[60] M. A. Pfaller, D. J. Diekema, D. L. Gibbs et al., "Candida krusei, a multidrug-resistant opportunistic fungal pathogen: geographic and temporal trends from the artemis disk antifungal surveillance program, 2001 to 2005," Journal of Clinical Microbiology, vol. 46, no. 2, pp. 515-521, 2008.

[61] W. R. Greco, G. Bravo, and J. C. Parsons, "The search for synergy: a critical review from a response surface perspective," Pharmacological Reviews, vol. 47, no. 2, pp. 331-385, 1995.

[62] D. N. Nandakumar, V. A. Nagaraj, P. G. Vathsala, P. Rangarajan, and G. Padmanaban, "Curcumin-artemisinin combination therapy for malaria," Antimicrobial Agents and Chemotherapy, vol. 50, no. 5, p. 1859, 2006.

[63] A. S. Collins, "Chapter 41. Preventing health care-associated infections," in Patient Safety and Quality: An Evidence-Based Handbook for NursesAgency for Healthcare Research and Quality, U.S. Department of Health and Human Services, Washington, DC, USA, 2009.

[64] R. Purwar, "Antimicrobial textiles," in The Impact and Prospects of Green Chemistry for Textile TechnologyElsevier, Amsterdam, Netherlands, 2018.

[65] G. Borkow and J. Gabbay, "Biocidal textiles can help fight nosocomial infections," Medical Hypotheses, vol. 70, no. 5, p. 990, 2008.

[66] K. Diba, "Identification of Candida species isolated from hospital acquired infections cases and hospital indoor environments," African Journal of Microbiology Research, vol. 619 pages, 2012.

[67] J. R. Wingard, W. G. Merz, M. G. Rinaldi, T. R. Johnson, J. E. Karp, and R. Saral, "Increase in Candida krusei infection among patients with bone marrow transplantation and neutropenia treated prophylactically with fluconazole," New England Journal of Medicine, vol. 325, no. 18, p. 1274, 1991. 
[68] S. B. Humayoun, L. M. Hiott, S. K. Gupta et al., "An assay for determining the susceptibility of Salmonella isolates to commercial and household biocides," PLoS One, vol. 13, no. 12, Article ID e0209072, 2018.

[69] P. J. Bremer, I. Monk, and R. Butler, "Inactivation of Listeria monocytogenes/Flavobacterium spp. biofilms using chlorine: impact of substrate, $\mathrm{pH}$, time and concentration," Letters in Applied Microbiology, vol. 35, no. 4, pp. 321-325, 2002.

[70] T.-F. C. Mah and G. A. O’Toole, "Mechanisms of biofilm resistance to antimicrobial agents," Trends in Microbiology, vol. 9, no. 1, pp. 34-39, 2001. 